\title{
Nouns and Verbs in the Brain: Grammatical Class and Task Specific Effects as Revealed by fMRI.
}

\author{
Manuela Berlingeri§, Davide Crepaldi§, Rossella Roberti§, Giuseppe \\ Scialfa\#, Claudio Luzzatti§ and Eraldo Paulesu§ \\ $\S_{\text {Department of Psychology, University of Milano-Bicocca, Italy }}$ \\ \#Neuroradiology Department, Ospedale Niguarda Ca' Granda, Milano
}

Short title: Noun and verb processing: an fMRI study

Corresponding author:

Claudio Luzzatti,

Department of Psychology, University of Milano-Bicocca

Piazza dell'Ateneo Nuovo 1

20126, Milano, Italy

Phone number: +390264483743

Fax number: +390264483706

E-mail: claudio.luzzatti@unimib.it 


\begin{abstract}
The wide variety of techniques and tasks used to study the neural correlates of noun and verb processing has resulted in a body of inconsistent evidence. We performed an fMRI experiment to detect grammatical class effects that generalize across tasks. Twelve subjects undertook a grammatical class switching task (GCST), in which they were presented with a noun (or a verb) and were asked to retrieve the corresponding verb (or noun), and a classical picture naming task (PNT) widely used in the previous aphasiological and imaging literature. The GCST was explicitly designed to ensure control over confounding variables, such as stimulus complexity or imageability. Conjunction analyses of the haemodynamic responses measured in the two tasks indicated a shared verb-related activation of a dorsal premotor and parietal network, pointing to a strong relationship between verb representation and action-oriented (visuo-)spatial knowledge. On the other hand, no brain area was consistently associated with nouns in both tasks. Moreover, there were task-dependent differences between noun and verb retrieval both at behavioural and at physiological level; the grammatical class that elicited the longest RTs in both tasks (i.e. verbs in the PNT and nouns in the GCST) triggered a greater activation of the left inferior frontal gyrus. Therefore, we suggest that this area reflects a general increase in task demand rather than verb processing per se.
\end{abstract}




\section{ACKNOWLEDGMENTS}

The study was supported by research grant $\mathrm{n}^{\circ}$ 2005109424/005 from the Ministero dell'Istruzione, dell'Università e della Ricerca (MIUR). Parts of this work have been presented at the $25^{\text {th }}$ European Workshop on Cognitive Neuropsychology, Bressanone (Italy), January 22-26, 2007. We thank the Editor of this special issue, Michele Miozzo, and two anonymous reviewers for comments and suggestions on an earlier draft of this article. 


\section{INTRODUCTION}

Since the mid 1980s, literature has concentrated on aphasic patients suffering from lexical retrieval difficulties predominantly affecting either nouns or verbs (e.g. Miceli, Silveri, Villa, \& Caramazza, 1984; McCarthy \& Warrington, 1985; Thompson, Shapiro, Li \& Schendel, 1994). Moreover, theoretical linguists describe nouns and verbs as being different lexical entities; indeed, they are affected by different syntactic phenomena (e.g. noun phrase movement vs. verb movement), have different morphological properties and different lexical and lexical-semantic representations (see for example Dowty, 1989; Levelt, Roelofs, \& Meyer 1999). Therefore the hypothesis that nouns and verbs have separate and diverse representation in the human mind and that cerebral brain damage may affect one while sparing the other appears to have a strong theoretical base.

In the last 20 years there has been a body of neuropsychological evidence supporting the view that nouns and verbs are differently represented in the cognitive system (e.g. Berndt, Mitchum, Haendiges, \& Sandson, 1997; Luzzatti, Raggi, Zonca, Pistarini, Contardi, \& Pinna, 2002; Aggujaro, Crepaldi, Pistarini, Taricco, \& Luzzatti, 2006; Crepaldi, Aggujaro, Arduino, Zonca, Ghirardi, Inzaghi, Colombo, Chierchia, \& Luzzatti, 2006). The noun-verb dissociations observed in aphasic patients have been explained in several different ways. According to Caramazza and colleagues (e.g., Rapp \& Caramazza, 2002), dissociated impairments may be caused by damage which selectively affects verbs or nouns at a late lexical stage (phonological or orthographical output lexicons); this is suggested by the fact that the patients participating in the study performed better on verbs in spoken production, and on nouns in written comprehension. Other researchers (e.g., Berndt, Mitchum, Haendiges \& Sandson, 1997) have claimed the existence of a lexical- 
syntactic representation of grammatical class at a more central lexical level (the lemma, see Levelt, Roelofs and Meier, 1999). Bird, Howard \& Franklin (2000), on the other hand, argued that noun-verb dissociation might be a semantic, rather than lexical, phenomenon; moreover, they suggested that many dissociations might be generated by an increased level of sensibility to imageability in aphasic patients. Finally, selective verb deficits have been explained as a consequence of syntactic damage (e.g., Friedmann, 2000) resulting from a pathological pruning of the syntactic tree which would prevent verbs from moving to the relevant functional categories and being inflected.

As the functional difference between the two grammatical classes received further substantiation, more and more attention was dedicated to the question of whether different neural circuits are responsible for noun and verb processing. In recent years many studies have tried to identify the brain areas underlying noun and verb processing using Positron Emission Tomography (PET; e.g. Warburton, Wise, Price, Weiller, Hadar, Ramsay, \& Frackowiak, 1996), functional Magnetic Resonance Imaging (fMRI; e.g. Tyler, Bright, Fletcher, \& Stamatakis, 2004), Magnetoencephalography (MEG; e.g. Sörös, Cornelissen, Laine, \& Salmelin, 2003), Transcranic Magnetic Stimulation (TMS; e.g. Cappa, Sandrini, Rossini, Sosta, \& Miniussi, 2002) and anatomo-clinical correlations (e.g. Aggujaro et al., 2006). However, the results of these studies do not seem to converge on a well-established pattern of cerebral areas (see Table 1 and Figure 1).

TABLE 1 ABOUT HERE

FIGURE 1 ABOUT HERE 
The lack of consistency in the functional imaging literature could be due to the wide variety of experimental and control conditions used; in fact, the cerebral basis of the lexical representation of nouns and verbs has been investigated through several tasks such as lexical decision, picture naming, semantic decision or fluency; it must also be said that a careful analysis of the cognitive levels called upon by the experimental task-baseline comparison has not always been carried out. In addition, the data obtained so far may well be influenced by the different statistical methods used and by the different sample sizes (see Table 1).

A further issue in the neuroimaging literature on nouns and verbs concerns lexicalsemantic variables (e.g., frequency, imageability, stimulus complexity). These variables have been found to be very important in predicting both the performance of aphasic patients (e.g. Nickels \& Howard, 1995) and the RTs of normal speakers on naming tasks (e.g. Bates, Burani, D’Amico, \& Barca, 2001). In particular, imageability is a very important lexical-semantic variable; not only does it have a strong influence on performance in lexical retrieval tasks, it also correlates with grammatical class. Indeed, there is a well-known constraint in picture naming tasks (PNT), whereby verbs usually have lower imageability than concrete nouns and pictures of nouns with comparable imageability would not elicit an unambiguous target word.

Nonetheless, imageability has received very little attention in neuroimaging studies, particularly in those focusing on noun and verb processing; only, two studies have considered imageability when investigating the brain areas underlying noun and verb processing.

Tyler, Russell, Fadili and Moss (2001) included imageability in their experimental design (Experiment 1) and matched nouns and verbs for this variable (Experiment 2). A 
lexical decision task (Exp 1) did not show any brain area that is sensitive to either grammatical class or imageability. This lack of imageability and grammatical class effect is at odds with the crucial role attributed to imageability by several neuropsychological studies (e.g., Bird et al., 2000, Luzzatti et al., 2002) and also with the neuroimaging evidence provided by Wise et al. (2000) showing an activation modulated by imageability in the left mid-fusiform gyrus, the inferior temporal gyrus and the left mid-superior temporal gyrus. Experiment 2, in which a semantic categorization task was used, gave very similar results, with no area emerging as specific for either nouns or verbs. Tyler and colleagues (2001) explain these results by suggesting that grammatical class effects arise only in tasks that require the use of grammatical class information for the purposes of morphological processing.

In the other study in which imageability was controlled (Bedny and Thompson-Schill, 2006), the authors compared a semantic decision task on written stimuli to passive viewing of a crosshair and found a significant grammatical-class-by-imageability interaction in the left inferior frontal gyrus and in the left middle temporal gyrus; these areas would respond more to verbs than nouns when stimuli are highly imageable, and more to nouns than verbs when stimuli are poorly imageable. The authors argued that this interaction could be explained by the number of meanings underlying a word; the more they are, the higher the activation of the left inferior frontal gyrus. As the number of meanings correlates positively with the imageability of verbs, but negatively with the imageability of nouns, this hypothesis would satisfactorily explain the grammatical-classby-imageability interaction. Therefore, the left inferior frontal gyrus might not be specific for grammatical class, but could come into play in the case of competition between alternatives during lexical access, resulting in a higher processing load (see Thompson- 
Schill et al., 1997).

Moreover, stimulus complexity and task difficulty (which influence resource demand) are two important factors to be considered in imaging studies of nouns and verbs; these factors may vary according to grammatical class. Take picture naming, for instance. While an object is represented with a single pictorial unit, the pictorial representation of verbs is much less direct, since it is impossible to actually draw actions. A picture eliciting a verb represents an agent performing an action in a specific context, often with a theme and a goal. Therefore, compared to nouns, the retrieval of a verb arguably requires extra-cognitive steps that may well be more onerous in terms of cognitive resources.

It is worth noting that not only are neuroimaging data on nouns and verbs from different studies barely consistent with each other, they are also quite at odds with those obtained from anatomo-clinical correlation studies on noun-verb dissociation in aphasia. In fact, previous studies have indicated predominant temporal damage for noun impairment (e.g. Damasio \& Tranel, 1993; Hillis, Tuffiash, Wityk, \& Barker, 2002), whereas neuroimaging evidence has also shown left premotor/prefrontal activation in noun processing, particularly when semantic tasks were used (e.g., Tyler, Stamatakis, Dick, Bright, Fletcher, \& Moss, 2003). The picture is even more intricate for verbs. In fact, lesion studies on verb-impaired aphasic patients frequently describe large lesions involving the left frontal cortex (see Daniele, Giustolisi, Silveri, Colosimo, \& Gainotti, 1994; Shapiro \& Caramazza, 2003), but there are several reports of verb-impaired patients whose lesions lie outside the left frontal regions (Daniele et al., 1994; Silveri \& Di Betta, 1997; Silveri, Perri, \& Cappa, 2003) and, more importantly, involve more posterior, temporo-parietal areas (e.g., Aggujaro et al., 2006). Furthermore, as reported in 
Figure 1, results from neuroimaging studies are also controversial, in some cases supporting left frontal involvement (Shapiro, Mottaghy, Schiller, Poeppel, Fluss, Muller, Caramazza, \& Krause, 2005), in others a major role of the left parietal areas (Martin, Haxby, Lalonde, Wiggs, \& Ungerleider, 1995) or crucial involvement of the inferior temporal regions (Tranel, Martin, Damasio, Grabowski, \& Hichwa, 2005); finally, there are studies that suggest a same network sub-serving nouns and verbs (Tyler, Russell, Fadili, \& Moss, 2001) or a similar network, but with verbs yielding stronger activation (Warburton et al., 1996).

\section{Aim of the study and experimental design}

A review of the neuropsychological and neuroimaging literature on nouns and verbs suggests the existence of both general and task-dependent grammatical class effects: the latter are most likely due to the fact that none of the tasks used so far permits a complete matching of all concomitant variables that can interfere with grammatical class effects (e.g., imageability and task complexity; see Crepaldi et al., 2006).

This circumstance calls for a factorial approach in which two lexical tasks are used; in such a design, any brain area underlying noun or verb lexical-semantic processing (irrespective of the concomitant variables) is expected to emerge in both conditions. A first task was chosen that permits a tight noun-verb matching of imageability and stimulus complexity (the Grammatical Class Switching Task, GCST); furthermore, picture naming of objects and actions (Picture Naming Task, PNT) was selected, as it stands out with regards to the amount of published work aimed at detecting behavioural and anatomical dissociations in noun and verb retrieval. Nevertheless, because of its intrinsic constraints, PNTs are imbalanced for some variables that can be matched in the 
GCST; in particular, stimuli available to elicit verbs and nouns in PNTs are imbalanced with regards to stimulus complexity and imageability. We therefore expected to observe grammatical class effects shared with the GCST as well as task-dependent grammatical class effects.

In conclusion, in order to examine the functional anatomical correlates of noun-verb processing, we adopted a factorial design with two tasks, both involving lexical-semantic processing with nouns or verbs. This design aims at identifying the brain areas that (i) show task-independent grammatical class effects (utilizing conjunction analyses between noun- and verb-specific areas observed in the two tasks) and (ii) are associated with task dependent responses (by determining task-by-grammatical-class interaction effects).

\section{MATERIALS AND METHODS}

\section{Subjects}

Twelve healthy, right-handed Italian students $(F=6, M=6)$ aged between 20-32 years [mean=25.5, $\mathrm{SD}=3.36]$, with at least 15 years of education [mean=16.6, $\mathrm{SD}=0.60$ ] participated in the experiment. None had any history of neurological disorders or learning disabilities; all gave their written consent to the experiment.

\section{Materials}

Task1: the Grammatical Class Switching Task (GCST)

45 Italian nouns and 45 corresponding verbs (e.g. applauso - applaudire, applause - to applaud; see Figure 2) were selected from the set used by Crepaldi et al. (2006). Each of the 45 noun-verb pairs were used to generate two different trials: in the noun-to-verb (N- 
to-V) condition, the participants were instructed to read the noun and to retrieve the corresponding verb silently, whereas in the verb-to-noun (V-to-N) condition, they were asked to read the verb and to retrieve the corresponding noun silently. The task was therefore composed of 90 trials, 45 of which elicited a verb, while the remaining 45 elicited a noun. The stimuli (font: Arial; size: 42; colour: black) were displayed in the centre of a computer screen on a white background; a question mark in the same font was added under each stimulus.

\section{FIGURE 2 ABOUT HERE}

All nouns and verbs were given and requested in their morphological base form, i.e. the infinitival form for verbs and the singular form for nouns (in Italian nouns and verbs are always inflected, even in the base form); nouns were also preceded by the article in order to disambiguate them from homophonous/homographic verbs. Twenty-seven verbs belonged to the first conjugation (-are verbs; e.g., saltare, to jump), 13 verbs to the second conjugation (-ere verbs; e.g., correre, to run) and five verbs to the third conjugation (-ire verbs; e.g., dormire, to sleep); this distribution reflects the proportion of the three conjugations in the entire Italian verb set (-are verbs $=70 \%$; -ere verbs $=19 \%$; -ire verbs $=11 \%$; see the BDVDB database, Thornton et al., 1997).

As reported in Table 2, nouns and verbs were matched for imageability (estimated on the basis of a sample of 21 normal subjects along a seven-point scale), number of letters, age of acquisition (estimated on the basis of a sample of 20 normal subjects along a ninepoint scale; Lotto, Dell'Acqua, \& Job, 2001) and surface frequency (taken from De Mauro, Mancini, Vedovelli, \& Voghera, 1993), while verbs have a higher number of 
syllables and have a significantly higher stem frequency than nouns (De Mauro, Mancini, Vedovelli, \& Voghera, 1993). Both imageability and age of acquisition ratings were collected by asking volunteers to judge printed words.

\section{TABLE 2 ABOUT HERE}

Though the GCST may appear to be a task that can be solved by the application of a morphological routine, it does require lexical access. Indeed, the GCST cannot be carried out by applying derivational sub-word-level rules because Italian verbs do not offer any cue to predict the appropriate deverbal morpheme among the several alternatives available. Take the verbs bombard-are (to bomb), calcol-are (to calculate) and camminare (to walk), for example; they are approximately the same length and belong to the same conjugation, but are nominalized through entirely different morphemes (bombardamento, bombardment; calcol-o, calculation; cammin-ata, walk). Therefore, the information on the correct derived forms must be stored at the lexical level, making lexical access necessary in order to carry out the noun-verb switch.

One may also argue that the activation triggered by the GCST reflects both noun and verb processing, as participants always read a noun when they were required to enunciate a verb, and a verb when they were required to enunciate a noun. However, the processing required by the input component of the GCST (the written cue) is very limited and much imaging evidence suggests that there is little activation for poorly processed components of a task (e.g., Rees, Frith and Lavie, 1997 or Rees and Lavie, 2001, for a review). 
The Picture Naming Task (PNT)

The PNT was devised of 45 object and 45 action drawings taken from the picture set used by Crepaldi et al. (2006; see Figure 2).

All the items included in the study had a name agreement of at least $85 \%$ (see Crepaldi et al., 2006). Table 3 summarizes the mean values for word length (letters and syllables), oral stem and surface frequency, imageability, age of acquisition, picture typicality and picture complexity; the former five variables were measured with the same procedure used for the GCST stimuli, whereas picture typicality and complexity were rated on a 1to-7 scale by 23 and 12 healthy volunteers, respectively. The two grammatical classes did not differ for oral word frequency, age of acquisition and picture typicality. As usual in PNTs, verbs were less imageable and pictorially more complex than nouns. Finally, verbs were slightly longer than nouns.

TABLE 3 ABOUT HERE

\section{Experimental procedure}

Subjects performed each experimental task three times prior to scanning in order to reduce uncertainty about the target response; these familiarization sessions were taken consecutively one to three hours prior to the fMRI scanning. During this phase, voiceonset times were recorded for each participant. The experimental procedure during this phase was the same as that used during the fMRI session; stimuli were presented in random order within each block in order to avoid sequence effects. The task order was balanced between the subjects in both the familiarization phase and in the fMRI session, 
with 6 participants performing the PNT before the GCST and 6 performing the GCST before the PNT.

During the fMRI session, stimuli were projected from a PC located outside the MR room, using Presentation 0.75 software. The stimuli were shown in the centre of a white screen. In each task the participants were exposed to the stimuli for one second, after which the screen went blank for one second (thus exposing the participants to one stimulus every two seconds). During the fMRI session subjects were instructed to perform each task silently in order to avoid artefacts due to mouth and head movements.

The fMRI design was based on alternating blocks of 10 scans of baseline and experimental tasks. Different baselines were used for the two experimental tasks; in particular, during the PNT rest period the subjects were shown a set of meaningless figures formed by scrambling the drawings used in the experimental condition. In addition, a geometric figure - either a $2 \mathrm{~cm}$ black square or a black circle $2 \mathrm{~cm}$ in diameter - was added to the centre of each scrambled picture and subjects were asked to name it (see Figure 2). As the scrambled stimuli were obtained from the experimental pictures, the elementary aspects of visual processing were matched between the experimental and the control condition.

During the GCST rest period, the subjects were shown a string of black squares with a circle in the central position or vice versa (Figure 2) and were asked to name the central geometrical figure. Ten series of strings of increasing length were used to balance the length of the words used in the experimental condition. In this case too a question mark was located under the string in order to balance the visual complexity of the stimuli used for the noun and verb condition. 


\section{fMRI data acquisition}

MRI scans were performed on a $1.5 \mathrm{~T}$ Marconi-Philips Infinion Scanner, using an Echo Planar Imaging (EPI) gradient echo sequence (Flip angle $90^{\circ} \mathrm{TE}=60 \mathrm{msec}, \mathrm{TR}=$ $3050 \mathrm{msec}, \mathrm{FOV}=240 \times 240$, matrix $=64 \times 64)$. The selected volume consisted of 26 contiguous transverse images (thickness $=5 \mathrm{~mm}$; gap $=0 \mathrm{~mm}$ ), acquired every 3.05 seconds. Each of the experiments described above generated 120 fMRI scans collected in alternating blocks of 10 baseline scans and 10 experimental task scans, each epoch lasting $30 "$.

\section{Data analysis}

\section{Behavioural data analysis}

The raw data were averaged across subjects and items; two separate data sets were then created (by-subject and by-item). The RTs of one of the 12 subjects participating in the experiment were not considered in the analyses as some artefacts occurred during the familiarization phase and so RT measurements were not completely reliable for this subject. Mean RTs at more than two standard deviations from the individual subject/item mean were also excluded from the analysis; this resulted in the elimination of $2 \%$ of the data from the by-item dataset and of $5 \%$ of the data from the by-subject dataset. The mean RTs were then inverse-transformed to obtain a more Gaussian-like distribution. In order to assess the effects of Task (2 levels; GCST vs. PNT), Session (3 levels: training session 1 vs. training session 2 vs. training session 3), Grammatical Class (2 levels: nouns vs. verbs) and their interactions, a three-way $(3 \times 2 \times 2)$ repeated-measure ANOVA was conducted on the by-subject dataset, whereas a three-way mixed-design ANOVA was run on the by-item dataset. 
Finally, two stepwise multiple regression analyses (MRA) were carried out on the inverse-transformed RTs for the PNT and the GCST (there is no a priori reason to assume that the same variables influenced the RTs in the two tasks), using the lexicalsemantic variables as covariates.

\section{fMRI data analysis}

First, a standard pre-processing was performed; this included the realignment of fMRI scans within each session and the normalization of the realigned images into the standard stereotaxic space. The stereotaxically normalized scans were then smoothed through a Gaussian filter of 10x10x10 mm to improve signal-to-noise ratio. The statistical analysis was performed by applying a general linear model: conditions were modelled in a blockdesign and the BOLD signal was convolved with a standard HRF as implemented in SPM2 (Friston, Holmes, Worsley, Poline, Frith, \& Frackowiak, 1995). Global differences in fMRI signal were compensated using proportional scaling for all voxels. High-pass filtering was used to remove confounding contributions to the fMRI signal, such as, for example, physiological noise from cardiac and respiratory cycles. The statistical analyses involved two steps. First, on each subject a fixed effect analysis was performed, in which condition-specific effects were calculated. These analyses generated contrast images containing the statistical information relative to the fMRI signal change as observed for a given statistical comparison, for each individual participant. Further, second-level ANOVAs conforming to random effect analyses were performed, in order to permit a generalization to the population level of the statistical inferences. The following condition-specific effects were estimated for each subject at the fixed effect analyses stage: (i) nouns-minus-baseline in the PNT; (ii) nouns-minus-baseline in the GCST; (iii) 
verbs-minus-baseline in the PNT; (iv) verbs-minus-baseline in the GCST. These effects are relatively unspecific as they are confounded with the functional anatomical correlates of the PNT and GCST. To characterize within these patterns those more specifically associated with noun and verb retrieval, and their interaction with task, the following comparisons were also performed:

(v) simple effects of nouns-minus-verbs and of verbs-minus-noun in the PNT;

(vi) the same effects in the GCST.

The contrast images derived from the above first-level analyses were then brought to a random-effect second level ANOVA. At this stage, the same effects were calculated at a group level. In addition we also calculated:

(vii) a conjunction of the specific activation of verbs-minus-noun and of nounsminus-verbs across both tasks;

(viii) a task-by-grammatical-class interaction effects.

In these second level group analyses, direct comparisons (e.g. verbs-minus-nouns in the PNT) were masked (using an inclusive mask, thresholded at $\mathrm{p}<0.05$ ) on the effect of the task of interest minus the baseline (e.g.: verbs-minus-nouns for the PNT masked on verbs-minus-scrambled pictures from the PNT). This was done to ensure that the activations emerging in the direct comparisons were not due merely to a de-activation in the baseline condition task; by doing so, any reported effect for a particular task effectively describes an activation that would also be replicated, at least as a trend, in a comparison with a further baseline.

For the same reason, the effects described at points (vii) and (viii) were masked on the four relevant simple effects (the threshold for the inclusive masks was $\mathrm{p}<.05$ ): for example the conjunction of verbs-minus-nouns across tasks, namely, the conjunction of 
verbs-minus-nouns in PNT and verbs-minus-nouns in GCST, was masked on verbsminus-baseline in PNT, verbs-minus-nouns in PNT, verbs-minus-baseline in GCST and verbs-minus-nouns in GCST.

All statistical comparisons are reported at a threshold of $\mathrm{p}<.001$ (uncorrected). The tables also indicate which foci survived the corrections for multiple comparisons offered by SPM2, i.e. the family-wise error rate (FEW) (Kiebel et al., 1999) and the false discovery rate (FDR) corrections (Genovese et al., 2002).

\section{RESULTS}

\section{Behavioural results}

Table 4 summarizes the mean RTs obtained by the subjects in the two tasks and the two grammatical classes along the three familiarization sessions.

Table 4 ABOUT HERE

The $3 \times 2 \times 2$ repeated-measures ANOVA (by-subject analysis) indicates a significant effect of session $(F[2,18]=13.26 ; \mathrm{p}<.001)$, task $(\mathrm{F}[1,9]=5.44 ; \mathrm{p}<.05)$ and task-bygrammatical-class $(\mathrm{F}[1,9]=54.68 ; \mathrm{p}<.001)$. The mixed-design ANOVA carried out on the by-item dataset shows exactly the same effects. Interestingly, the task-by-grammaticalclass interaction reflects faster response to nouns in the PNT task $(\mathrm{t}=3.18, \mathrm{df}=87$, $\mathrm{p}<.005)$, but faster responses to verbs in the GCST task $(\mathrm{t}=-7.09, \mathrm{df}=85, \mathrm{p}<.001$; see Table 4). 
Table 5 and Table 6 report the results of the stepwise multiple regression analyses for the GSCT and the PNT respectively. Surface and stem frequency were so tightly correlated in both tasks that their individual contributions could not be assessed in a multiple regression analysis (Table 7); thus, only stem frequency was inserted in the regression models. A tight correlation also emerged between number of letters and number of syllables; thus, only number of letters was included in the linear models. None of the variables influenced RTs in the GCST (Table 5), while only imageability was a significant predictor in the PNT (Table 6).

TABLE 5 ABOUT HERE

TABLE 6 ABOUT HERE

TABLE 7 ABOUT HERE

\section{fMRI results}

The grammatical class switching task

The simple effect of nouns (minus baseline) showed significant activation of a large left frontal network, of the left superior temporal pole, the right and left inferior temporal gyrus, the left inferior parietal lobule and the left superior, middle and inferior occipital gyri. The verbs-minus-baseline comparison was associated with increment of the BOLD signal in the precentral gyrus bilaterally, the left supplementary motor area (SMA), the right middle temporal pole, the left superior temporal gyrus, the middle and inferior 
temporal gyri bilaterally, the left supramarginal and angular gyri and the lingual gyrus bilaterally (see Table 8 and Figure 3).

Direct comparisons between the two grammatical classes revealed that, when compared to verbs, nouns activate the left inferior frontal gyrus, the left inferior parietal lobule, the left precuneus and the left middle and superior occipital gyri (Table 6 and Figure 4), while verbs were associated with increased BOLD signal in a bilateral frontal network - including the superior frontal gyrus, the precentral gyrus and the SMA - and in a right parietal network - including the postcentral gyrus, the paracentral lobule and the precuneus (see Table 8 and Figure 3).

TABLE 8 ABOUT HERE

FIGURE 3 ABOUT HERE

The picture naming task

The simple effect of nouns versus the corresponding baseline was associated with an increase in the BOLD signal in the right inferior temporal gyrus, in the left superior occipital gyrus and in the inferior occipital gyrus bilaterally, whereas verbs versus the corresponding baseline showed activation not only in the right and left occipital regions and in the right inferior temporal gyrus, but also in the left inferior frontal gyrus, in the right cuneus, in the left fusiform gyrus and in the lingual gyrus bilaterally (see Table 9 and Figure 3). 
Direct comparisons showed that while nouns did not activate any area to a larger extent than verbs did, these latter were associated with larger activation in the left inferior frontal gyrus, in the left insula and in posterior regions including the right and left superior and middle occipital gyri, the left lingual gyrus, the bilateral middle temporal gyrus, the right inferior temporal and the dorsal part of the right and left posterior parietal gyri (Table 9 and Figure 3).

\section{TABLE 9 ABOUT HERE}

\section{Across-task activations for nouns and verbs}

These activations were explored through the conjunction analyses described in the methods section. In both tasks verbs were associated with a significant increment of the BOLD signal in the precentral and postcentral gyri bilaterally, in the right SMA, in the right inferior parietal lobule and, bilaterally, in the paracentral lobule, in the superior parietal lobule and in the precuneus (see Table 10 and figure 4). On the contrary, no significant activation emerged when combining nouns-minus-verbs and nouns-minusbaseline conditions in the PNT and in the GCST.

TABLE 10 ABOUT HERE

FIGURE 4 ABOUT HERE 


\section{Task-by-grammatical-class interaction effects}

Significant task-by-grammatical-class interaction effects emerged in the left inferior frontal cortex, the left insula, the left inferior temporal gyrus and the occipital cortex bilaterally: these areas were systematically more active for verb retrieval in the PNT and for noun retrieval in the GCST (see Table 11 and Figure 5). On the contrary, there was no opposite interaction effect, i.e. no areas were more active for nouns in the PNT and for verbs in the GCST.

TABLE 11 ABOUT HERE

FIGURE 5 ABOUT HERE

\section{DISCUSSION}

As reported in the Introduction, previous evidence on the brain areas underlying noun and verb processing is far from representing a clear picture; this may be because in most studies (i) the specification of the cognitive processes entailed by the experimental and control tasks were sub-optimal and (ii) the experimental designs were not controlled for confounding factors, like imageability and task complexity.

Our study aims at assessing these issues by investigating noun and verb retrieval while controlling for spurious factors. We used two different tasks for this purpose: a noun and verb production task (Grammatical Class Switching Task, GCST) and the most widely used picture naming task (PNT). This experimental design allowed us to determine which brain regions are consistently associated with nouns or verbs across tasks; these areas 
were identified by conjunction analyses of the grammatical-class-specific activations in the two tasks. The same design allowed us to identify those brain regions that show a task-dependent grammatical class effect or, in other words, a task-by-grammatical-class interaction effect. Interestingly, the fMRI interaction effects were associated with behavioural effects, which we will take as the starting point of our discussion.

\section{Behavioural data: the RTs analysis}

The analysis of the RTs reveals a consistent and significant shortening during the familiarization phase. Moreover, there was no interaction between session and grammatical class or task; this lack of interaction shows that RTs shortened homogeneously along the familiarization sessions without introducing any artificial distortion between different experimental conditions. These results suggest that pre-fMRI familiarization was not associated with a grammatical-class specific adaptation in the functional imaging results.

The RT analysis also revealed that nouns were retrieved faster than verbs in the PNT and slower than verbs in the GCST. This interaction effect is in line with the taskdependent grammatical class effects described in three patients by Crepaldi et al. (2006) and can be explained as follows. Slower verb retrieval in the PNT can arguably be attributed to the fact that the relationship between verbs and their corresponding pictorial representation is weaker than it is for nouns. Indeed, as already mentioned in the Introduction, it is not possible to depict the action of "eating" per se; at best the sketch would represent a person with his/her mouth open, some food, and maybe a table and a chair at which and on which the person is sitting; but the actual action of "eating" is more than the sum of the individual agent, theme and possible adjuncts. In other words, in 
order to retrieve a verb in a PNT, the arguments of the event (e.g. agent, theme/goal) must be identified, their relationships processed, the underlying action singled out and the corresponding lexical entry retrieved. All these cognitive steps have a cost in terms of time and do determine a higher task demand.

On the other hand, slower RTs for nouns were not necessarily predicted in the GCST, but they can be explained as follows. Italian has more than ten de-verbal derivational suffixes (e.g. -io in mormorio-mormorare (to mumble), -ime in mangime-mangiare (to eat), -mento in bombardamento-bombardare (to bomb), -anda in bevanda-bere (to drink), -nza in speranza-sperare (to hope), -ta in fermata-fermare (to stop), -uta in caduta-cadere (to fall), -zione in informazione-informare (to inform)); therefore, when generating a noun from a verb, there are many possible alternatives, of which only one is an existing noun. On the contrary, verbs have only three possible endings (-are, -ere, -ire). As a result, the search for nouns is more demanding than for verbs, and this may have determined longer RTs when producing nouns in the GCST.

In both cases (i.e., verb production in the PNT and noun production in the GCST), a higher cognitive demand can account for the different response times elicited by the two grammatical classes.

However, the grammatical-class-by-task interaction may also depend on the effect of lexical-semantic variables, particularly of imageability (unmatched in the PNT) and word frequency (unmatched in the GCST) and so a Multiple Regression Analysis (MRA) was carried out to assess the impact of these factors. Although MRA suggests a role for these variables (imageability is a significant predictor in the PNT), in themselves they are not sufficient to explain the interaction effect for at least two reasons. While the imbalanced variable influences RTs in the PNT (where imageability is a significant predictor), this is 
not the case in the GCST (where word frequency is not a significant factor); moreover, neither imageability nor word frequency (nor any other variable) explains RTs in both tasks.

Altogether, the interaction which emerges in the behavioural data seems best explained in terms of task demand, although imageability and frequency may play an additional (though less relevant) role.

\section{Neuroimaging data}

The exploration of the simple effects reported in Tables 8 and 9 and in Figure 3, i.e., the comparisons against baselines and the direct comparison between "noun" and "verb" scans, shows a large number of brain regions, some of which are systematically associated with a given grammatical class, while some other appear to activate in a taskdependent manner.

The following discussion will briefly remark on the brain areas activated in the single tasks and then will focus on the conjunction analysis of the grammatical class effects across tasks and on the analysis of the task-by-grammatical-class interaction effects: these latter allow us to make inference about commonalities and differences between grammatical classes, tasks, and their interactions.

\section{Neuroimaging data: the GSCT}

When compared with the baseline, noun retrieval in the GCST activates a leftlateralized pattern of areas, including the inferior frontal gyrus, the middle frontal gyrus, the precentral gyrus, the temporal pole, the inferior temporal gyrus, the inferior parietal lobule and the superior, middle and inferior occipital gyri (Table 8). This very extensive pattern of activation for nouns is quite in line with the brain areas described in a lexical 
decision task by Fujimaki, Miyauchi, Putz, Sasaki, Takino, Sakai, \& Tamada (1999) and is larger than those usually emerging in PNTs (e.g. Tranel et al., 2005a). Verbs in the GCST were also associated with a fairly wide network, involving some areas that were activated also by nouns (left precentral gyrus, left and right inferior temporal gyrus and bilateral lingual gyrus), but also others that were not (left SMA, middle cingulate gyrus and left angular and supramarginal gyri; see Table 8). Compared with verbs, nouns activate the left inferior frontal gyrus, the left inferior parietal lobule and the left precuneus, whereas, compared with nouns, verbs activate the precentral gyrus and the SMA bilaterally, and a right-hemisphere parietal network including the post-central gyrus, the paracentral lobule and the precuneus (Table 8).

The noun- and verb-related networks that emerge in the GCST are not completely consistent with the brain areas frequently reported as specific for one of the two grammatical classes. For instance, the left inferior frontal gyrus has been mostly reported to be associated with verbs (e.g. Chao \& Martin, 2000, Tyler et al., 2003). Our results rather agree with those reported by Bedny \& Thompson-Schill (2006), which reveal complex grammatical-class-by-imageability interaction, according to which the left inferior frontal gyrus is more active for nouns if the items are low in imageability, but for verbs if the items are high in imageability. As our GCST stimuli were particularly low in imageability, a noun-specificity for the left inferior frontal gyrus is not surprising. Moreover, the GCST reveals that the parietal areas play an important role in verb processing; although a number of experiments have showed parietal activations for verbs (e.g. Shapiro, Moo, \& Caramazza 2006; Chao \& Martin, 2006), these areas have always been found in association with more predominant frontal networks and, consequently, their cognitive role in verb processing has been only marginally addressed. 
Previous neuroimaging studies on noun retrieval that used a PNT to elicit responses have highlighted the contribution of several left-hemisphere areas, including the parahippocampal and fusiform gyri, the inferior temporal gyrus, the medio-temporal gyrus, the insula, the inferior frontal cortex and the precentral gyrus (e.g. Chao \& Martin, 2000; Tranel, Grabowski, Lyon, \& Damasio, 2005; Saccuman, Cappa, Bates, Arevalo, Della Rosa, Danna, \& Perani, 2006). A very different pattern emerged in the present study when the noun-retrieval condition was compared with the baseline: an activation of the right inferior temporal gyrus, of the left superior occipital gyri and of the inferior occipital gyrus bilaterally was found (Table 9). This difference could be due to the fact that previous studies used passive viewing as a baseline, whereas the control task employed in this study required the silent retrieval of a semi-automatic response (either "square" or "circle"), arguably allowing the subtraction of any of the post-lexical cognitive processes, such as phonological implementation, syllabification and, eventually, articulation.

When comparing the action-naming condition to the baseline, a significant activation emerged in the left inferior frontal gyrus, the right inferior temporal gyrus, the right cuneus, the bilateral superior, middle and inferior occipital gyri, the left fusiform gyrus and the lingual gyrus bilaterally (Table 9). As the baseline subtracted the contribution of post-lexical processes from the activation (see previous paragraph), these results can be properly compared only with those from Damasio, Grabowski, Tranel, Ponto, Hichwa, \& Damasio (2001). The patterns emerging in the two studies only overlap in the left inferior frontal gyrus. We found a verb-related activation of the most posterior portion of the right inferior temporal gyrus, which has not been observed previously; however Damasio et al. 
(2001) did find significant activation slightly further up in the right middle occipital gyrus at its junction with the middle temporal gyrus.

Compared to verbs, nouns did not activate any specific brain region. Verbs, on the contrary, were associated with increased activation of a rather large bilateral pattern including the left inferior frontal gyrus, the left insula, the left middle temporal gyrus, the right inferior temporal gyrus, the bilateral middle occipital gyri and the left lingual gyrus (see Table 9). These findings seem to suggest that noun retrieval does not recruit different and specific areas as compared to verbs and is sub-served by a somewhat smaller and quantitatively less activated network in the same brain regions: this result is in line with the conclusions drawn by Warburton et al. (1996). For what concerns the verb-specific areas, occipital activation is arguably due to the greater stimulus complexity characterizing action pictures compared to object pictures; in fact, action pictures always include an agent and often a theme/goal. The verb-specific activation found in the left inferior frontal gyrus and the left insula is in line with a number of previous studies (e.g. Perani, Cappa, Schnur, Tettamanti, Collina, Rosa, \& Fazio, 1999; Tyler et al., 2004), but has never been reported in verbs-minus-nouns direct comparison in picture naming. Only Tranel et al. (2005b) found left middle temporal activation in the verbs-minus-nouns direct comparison.

\section{The conjunction analyses: Grammatical class replicable effects}

The conjunction analysis carried out for verbs showed an across-task replicable verbspecific activation of the right and left precentral and postcentral gyri, of the right SMA and of the paracentral lobule, the superior parietal lobule, the inferior parietal lobule and the precuneus bilaterally. Since the premotor and superior parietal areas are known to be 
crucial for the formation of motor representation in observational learning (e.g. Frey \& Gerry, 2006), for visuo-motor integration and for the planning of object-related action (Grefkes \& Fink, 2005), our results indicate that lexical and lexical-semantic representation of verbs are strictly connected with action-oriented (visuo-)spatial brain networks. Furthermore, it should be considered that our tasks included verbs with a prominent motor component, like nuotare (to swim) and verbs denoting actions which require finely-tuned hand movements, like accarezzare (to caress), but also verbs denoting more automatic actions like starnutire (to sneeze) and verbs denoting actions that can be realized by fully different motor engrams (like sollevare, to lift, in lifting a finger, lifting an arm, lifting a couch or lifting a case through a pulley), making their conceptual representation unlikely to be based on specific motor representations. Therefore, our results suggest that lexical-semantic verb representations are related to action-oriented spatial knowledge even when verbs with low degree of actionality are considered together with proper action verbs. A further experiment using separate groups of verbs with different degree of actionality should be carried out to test whether this superior parietal verb-related network can be further dissected into smaller functional subsets.

The activation emerging in the precentral and postcentral gyri is in line with the results reported by Hauk, Johnsrude \& Pulvermuller (2004) and seems to confirm a relationship between lexical-semantic verb representations and sensori-motor knowledge. However, the concomitant emergence of extensive more posterior parietal activation seem to confirm a primary role of these latter areas in storing (and/or processing) action-related lexical and lexical-semantic knowledge. 
We found no noun-specific activation across tasks; this was evident from the conjunction analyses that failed to reveal a noun-specific brain network activated over and above the verb network in both the GCST and the PNT. This finding is line with the results reported by Hernandez, Dapretto, Mazziotta and Bookheimer (2001) and by Tyler et al. (2001). This lack of noun-specific areas may be explained at least in part by the different imageability ratings of nouns in the PNT (highly imageable) and in the GCST (poorly imageable, as they had to be matched with verbs). This interpretation is suggested by Bedny \& Thompson-Schill's (2006) results, which show that both noun- and verbspecific activations vary according to the imageability of the stimuli.

The task-by-grammatical-class interaction: The role of the left inferior frontal gyrus

The left inferior frontal gyrus and the left insula are strongly activated by verbs in the PNT; these areas could therefore be considered as verb-specific. This hypothesis would imply the activation of these areas in any task involving lexical access to verbs, and in particular in the GCST. However, as can be seen from Table 10, this is not the case.

As proposed by Thompson-Schill et al. (1997), Snyder et al. (2007) and Bedny et al. (2007), there is an alternative hypothesis suggesting that activation in the left inferior frontal gyrus reflects higher cognitive demand of the task and the presence of several different alternatives to select among rather than verb-specific lexical-semantic processing. As already argued in the Introduction and in the Discussion of the behavioural data, verbs impose higher task demand than nouns in the PNT, due to a less direct relationship between lexical entries and the corresponding pictures. Nouns, on the contrary, impose higher selection demands in the GCST in Italian, since a higher number of derivational affixes are available to produce a noun from a verb than a verb from a 
noun. In addition, in the PNT verbs were less imageable and longer than nouns, whereas in the GCST nouns were less frequent than verbs; this mismatch may have contributed to further increase the task demand imposed by verbs in the PNT and by nouns in the GCST.

Altogether, the fMRI data support the hypothesis that activation of the left inferior frontal gyrus reflects task demand and is therefore associated with verbs in the PNT and with nouns in the GCST. This is also perfectly in line with the behavioural data: the double dissociation observed between the two tasks in the RT analysis reflects the different processing load for nouns and verbs and fully parallels the task-by-grammaticalclass interaction found in the left inferior frontal gyrus and in the left insula.

This interpretation is also in line with the neuropsychological study by Crepaldi, Aggujaro, Arduino, Zonca, Ghirardi, Inzaghi et al. (2006). As for the present study, these authors have tested noun-verb dichotomy with two different tasks: a classical Picture Naming Task (PNT) and the Noun and Verb Retrieval task in Sentence Context (NVRSC), a task that is very similar to the GCST. Three patients were more impaired for verbs in the PNT, but for nouns in the NVR-SC; considering the similarity between the NVR-SC and the GCST, Crepaldi et al.'s (2006) results mirror the grammatical-class-bytask interaction observed in the present study (both in terms of fMRI and behavioural data) and gives further evidence of task-dependent grammatical class effects. 


\section{CONCLUSION}

Brain areas associated with either noun or verb processing depend largely on the specific task used to elicit their retrieval and may be influenced by the lower degree of imageability and the higher stimulus complexity characterizing verbs in picture naming.

In this study we showed that bilateral premotor and superior parietal activation emerges in relation to verbs across both tasks; this suggests that verb representation relies on action-oriented (visuo-)spatial knowledge.

Moreover, the task-by-grammatical-class interaction clearly shows that the activation of the left inferior frontal gyrus and of the left insula, which have been frequently found to be crucial for verb processing, is associated with verb retrieval in the PNT, but with noun retrieval in the GCST, mirroring the double dissociation that emerged in the RT analysis between nouns and verbs in the two tasks. This observation, together with theoretical considerations regarding the cognitive processes underlying noun and verb retrieval in the PNT and in the GCST, suggests that activation in the left inferior frontal gyrus and in the left insula reflects higher cognitive demands of the task rather than a verb-specific lexical or lexical-semantic. 


\section{REFERENCES}

Aggujaro, S., Crepaldi, D., Pistarini, C., Taricco, M., \& Luzzatti, C. (2006). Neuroanatomical correlates of impaired retrieval of verbs and nouns: Interaction of grammatical class, imageability and actionality. Journal of Neurolinguistics, 19, 175194.

Bedny, M., \& Thompson-Schill, S.L. (2006). Neuroanatomically separable effects of imageability and grammatical class during single-word comprehension. Brain and Language, 98, 127-139.

Bedny, M., Hulbert, J.C., \& Thompson-Schill, S.L. (2007). Understanding words in context: the role of Broca's area in word comprehension. Brain research, 1146, 101114.

Berndt, R.S., Mitchum, C.C., Haendiges, A.N., \& Sandson, J. (1997). Verb retrieval in aphasia. 1. Characterizing single word impairments. Brain and Language, 56, 68106.

Cappa, S.F., Sandrini, M., Rossini, P.M., Sosta, K., \& Miniussi, C. (2002). The role of the left frontal lobe in action naming: rTMS evidence. Neurology, 59, 720-723.

Chao, L.L., \& Martin, A. (2000). Representation of Manipulable Man-Made Objects in the Dorsal Stream. NeuroImage, 12, 478-484.

Crepaldi, D., Aggujaro, S., Arduino, L.S., Zonca, G., Ghirardi, G., Inzaghi, M.G., Colombo, M., Chierchia, G., \& Luzzatti, C. (2006). Noun-verb dissociation in aphasia: The role of imageability and functional locus of the lesion. Neuropsychologia, 44, 73-89. 
Damasio, H., Grabowski, T.J., Tranel, D., Ponto, L.L.B., Hichwa, R.D., \& Damasio, A.R. (2001). Neural correlates of naming actions and of naming spatial relations. Neuroimage, 13, 1053-1064.

Damasio, A.R., \& Tranel, D. (1993). Nouns and verbs are retrieved with differently distributed neural systems. Proceedings of the National Academy of Science (USA), $90,4957-4960$.

Daniele, A., Giustolisi, L., Silveri, M.C., Colosimi, C., \& Gainotti, G. (1994). Evidence for a possible neuroanatomical basis for lexical processing of nouns and verbs. Neuropsychologia, 32, 1325-1341.

De Mauro, T., Mancini, F., Vedovelli, M., \& Voghera, M. (1993). Lessico di Frequenza dell'Italiano Parlato. Milano, Italy: ETAS Libri.

Dowty, D. (1989). On the semantic content of the notion of 'thematic role'. In G. Chierchia, B. Partee, \& R. Turner (Eds.), Properties, Types and Meaning (pp. 69129). Dordrecht, Netherlands: Kluwer.

Frey, S.H., \& Gerry, V.E. (2006). Modulation of neural activity during observational learning of actions and their sequential orders. The Journal of Neuroscience, 26, $13194-13201$.

Friston, K.J., Holmes, A., \& Worsley K.J., Poline, J.P., Frith C.D., \& Frackowiak R.S.J. (1995). Statistical parametric maps in functional imaging: a general linear approach. Human Brain Mapping, 2, 189-210.

Fujimaki, N., Miyauchi, S., Putz, B., Sasaki, Y., Takino, R., Sakai, K., \& Tamada, T. (1999). Functional magnetic resonance imaging of neural activity related to orthographic, phonological, and lexico-semantic judgments of visually presented characters and words. Human Brain Mapping, 8, 44-59. 
Genovese, C., Lazar, N. \& Nichols, T. (2002). Thresholding of statistical maps in functional neuroimaging using the false discovery rate. Neuroimage, 15, 870-878.

Grefkes, C., \& Fink, G.R. (2005). The functional organization of the intraparietal sulcus in humans and monkeys. Journal of Anatomy, 207, 3-17.

Grossman, M., Koenig, P., DeVita, C., Glosser, G., Alsop, D., Detre, J., \& Gee, J. (2002). Neural representation of verb meaning: An fMRI study. Human Brain Mapping, 15, 124-134.

Hauk, O., Johnsrude, I., \& Pulvermuller, F. (2004). Somatotopic representation of action words in human motor and premotor cortex. Neuron, 41, 301-307.

Hernandez, A., Dapretto, M., Mazziotta, J., \& Bookheimer, S. (2001). Language switching and language representation in Spanish-English bilinguals: An fMRI study. Neuroimage, 14, 510-520.

Hillis, A.E., Tuffiash, E., Wityk, R.J., \& Barker, P.B. (2002). Regions of neural dysfunction associated with impaired naming of actions and objects in acute stroke. Cognitive Neuropsychology, 19, 523-534.

Kiebel, S., Poline, J., Friston, K.J., Holmes, A., \& Worsley, K. (1999) Robust smoothness estimation in statistical parametric maps using standardized residuals from the general linear model. Neuroimage, 10, 756-766.

Levelt, W. J. M., Roelofs, A., \& Meyer, A. S. (1999). A theory of lexical access in speech production. Behavioral and Brain Sciences, 22, 1-75.

Lotto, L., Dell'Acqua, R., \& Job, R. (2001). The psycholinguistic database/department of psychology of development and socialization figures: Measurement of accord of name, type, familiarity, acquisition, and naming time for 266 figures. Giornale Italiano di Psicologia, 28, 193-207. 
Luzzatti, C., Raggi, R., Zonca, G., Pistarini, C., Contardi, A., \& Pinna, G.D. (2002). Verb-Noun double dissociation in aphasic lexical impairments: The role of word frequency and imageability. Brain and Language, 81, 432-444.

Martin, A., Haxby, J.V., Lalonde, F.M., Wiggs, C.L., \& Ungerleider, L.G. (2005). Discrete cortical regions associated with knowledge of color and knowledge of action. Science, 270, 102-105.

McCarthy, R., \& Warrington, E.K. (1985). Category specificity in an agrammatic patient: the relative impairment of verb retrieval and comprehension. Neuropsychologia, 23, 709-727.

Miceli, G., Silveri, M.C., Villa, G., \& Caramazza, A. (1984). On the basis for the agrammatic's difficulty in producing main verbs. Cortex, 20, 207-240.

Nickels, L., \& Howard, D. (1995). Aphasic naming: what matters? Neuropsychologia, 33, $1281-1303$

Perani, D., Cappa, S.F., Schnur, T., Tettamanti, M., Collina, S., Rosa, M.M., \& Fazio, F. (1999). The neural correlates of verb and noun processing. A PET study. Brain, $122,2337-2344$.

Rees, G., Frith, C.D., \& Lavie, N. (1997). Modulating irrelevant motion perception by varying attentional load in an unrelated task. Science, 278, 1616-1619.

Rees, G., \& Lavie, N. (1997). What can functional imaging reveal about the role of attention in visual awareness? Neuropsychologia, 39, 1343-1353.

Rowan, A., Liégeois, F., Varga-Khadem, F., Gadian, D., Connelly, A., \& Baldeweg, T. (2004). Cortical lateralization during verb generation: a combined ERP and fMRI study. Neuroimage, 22, 665-675. 
Saccuman, M.C., Cappa, S.F., Bates, E.A., Arevalo, A., Della Rosa, P., Danna, M., \& Perani, D. (2006). The impact of semantic reference on word class: An fMRI study of action and object naming. NeuroImage, 32, 1865 - 1878

Shapiro, K., \& Caramazza, A. (2003) The representation of grammatical categories in the brain. Trends in Cognitive Sciences, 7, 201-206.

Shapiro, K, Moo, L.R., \& Caramazza, A. (2006). Cortical signatures of noun and verb production. Proceedings of the National Academy of Sciences, 103, 1644-1649.

Shapiro, K., Mottaghy, F.M., Schiller, N.O., Poeppel, T.D., Fluss, M.O., Muller, H.W., Caramazza, A., \& Krause, B.J. (2005). Dissociating neural correlate for verbs and nouns. Neuroimage, 24, 1058-1067.

Shetreet, E., Palti, D., Friedmann, N., \& Hadar, U. (in press). Cortical representation of verb processing in sentence comprehension: number of complements, subcategorization, and thematic frames. Cerebral Cortex.

Silveri, M.C., \& Di Betta, A.M. (1997). Noun-verb dissociations in brain-damaged patients: further evidence. Neurocase, 3, 477-488.

Silveri, M., Perri, R., \& Cappa, A. (2003). Grammatical class effects in brain-damaged patients: Functional locus of noun and verb deficit. Brain and Language, 85, 49-66.

Snyder, H.R., Feigenson, K., \& Thompson-Schill, S.L. (2007). Prefrontal cortical response to conflict during semantic and phonological tasks. Journal of cognitive neuroscience, 19, 761-775.

Sörös, P., Cornelissen, K., Laine, M., \& Salmelin, R. (2003). Naming actions and objects: cortical dynamics in healthy adults and in an anomic patient with a dissociation in action/object naming. Neuroimage, 19, 1787-1801. 
Thompson, C.K., Shapiro, L.P., Li, L., \& Schendel, L. (1994) Analysis of verbs and verb-argument structure: A method for quantification of aphasic language production. In Lemme, P. (Eds.), Clinical Aphasiology. Austin, TX: Pro-Ed.

Thompson-Schill, S.L., D'Esposito, M., Aguirre, G.K., \& Farah, M.J. (1997). Role of the left inferior frontal cortex in retrieval of semantic knowledge: A re-evaluation. Proceedings of the National Academy of Science, 94, 14792-14797.

Thornton, A.M., Iacobini, C., \& Burani, C. (1997). BDVDB. Una base di dati per il vocabolario di base della lingua italiana. $2^{a}$ edizione. [BDVDB: A database for the Italian basic dictionary. 2nd Edition]. Roma: Bulzoni.

Tranel, D., Grabowski, T.J., Lyon, J., \& Damasio, H. (2005). Naming the same entities from a visual or from auditory stimulation engages similar regions of left inferotemporal cortices. Journal of Cognitive Neuroscience, 17, 1293-1305.

Tranel, D., Martin, C., Damasio, H., Grabowski, T.J., \& Hichwa, R. (2005). Effects of noun-verb homonymy on the neural correlates of naming concrete entities and actions. Brain and Language, 92, 288-299.

Tyler, L.K., Bright, P., Fletcher, P., \& Stamatakis, E.A. (2004). Neural processing of nouns and verbs: the role of inflectional morphology. Neuropsychologia, 42, 512523.

Tyler, L.K., Russell, R., Fadili, J., \& Moss, H.E. (2001). The neural representation of nouns and verbs: PET studies. Brain, 124, 1619-1634.

Tyler, L.K., Stamatakis, E.A., Dick, E., Bright, P., Fletcher, P., \& Moss, H.E. (2003).Objects and their actions: evidence for a neurally distributed semantic system. NeuroImage, 18, 542-557. 
Warburton, E., Wise, R.J.S., Price, C.J., Weiller, C., Hadar, U., Ramsay, S., \& Frackowiak, S.J. (1996). Noun and verb retrieval by normal subjects, Studies with PET. Brain, 119, 159-179. 
Table 1. PET and fMRI studies on nouns and verbs reported so far in the literature.

\begin{tabular}{|c|c|c|c|c|c|c|c|c|}
\hline Authors & Technique & $\begin{array}{c}\text { Sample } \\
\text { size }\end{array}$ & Threshold & Design & Experimental task & Baseline & Contrast & Area \\
\hline \multirow[b]{2}{*}{$\begin{array}{l}\text { Perani et al. } \\
\text { (1999) }\end{array}$} & \multirow[b]{2}{*}{ PET } & \multirow[b]{2}{*}{14} & \multirow[b]{2}{*}{$\begin{array}{c}.001 \\
\text { uncorrected }\end{array}$} & \multirow[b]{2}{*}{$\begin{array}{l}\text { Block } \\
\text { design }\end{array}$} & \multirow[b]{2}{*}{ Lexical decision } & \multirow[b]{2}{*}{ Letter detection task } & Nouns-Verbs & No area \\
\hline & & & & & & & Verbs-Nouns & $\begin{array}{l}\text { L mid. and inf. Frontal gyrus; L sup Parietal } \\
\text { lobule; L mid. and inf. Temp gyrus; L inf. } \\
\text { Occipital gyrus. }\end{array}$ \\
\hline \multirow[t]{2}{*}{$\begin{array}{l}\text { Fujimaki et al. } \\
\text { (1999) }\end{array}$} & \multirow[t]{2}{*}{ fMRI } & \multirow[t]{2}{*}{7} & \multirow{2}{*}{$\begin{array}{l}\text { Cross- } \\
\text { correlation } \\
\text { coefficient, } \\
\text { equivalent } \\
\text { to } .005 \\
\text { uncorrected }\end{array}$} & \multirow[t]{2}{*}{$\begin{array}{l}\text { Block } \\
\text { design }\end{array}$} & \multirow[t]{2}{*}{ Lexical decision } & \multirow[t]{2}{*}{$\begin{array}{l}\text { Line orientation } \\
\text { judgement }\end{array}$} & Noun-baseline & $\begin{array}{l}\text { L Broca's area, L Insula, L ant. Cingulate } \\
\text { sulcus, Precentral sulcus (bilaterally), L } \\
\text { Postcentral sulcus, bilateral Intraparietal } \\
\text { sulcus, L Supramarginal gyrus, bilateral } \\
\text { Occipito-Temporal sulcus, R BA 46-47 }\end{array}$ \\
\hline & & & & & & & Verb-baseline & $\begin{array}{l}\text { Bilateral Broca's area, Insula and BA 46, } \\
\text { bilateral Precentral sulcus, L Postcentral } \\
\text { sulcus, bilateral Intraparietal sulcus, L } \\
\text { Supramarginal gyrus, Precuneus, bilateral } \\
\text { Occipito-temporal sulcus. }\end{array}$ \\
\hline \multirow{6}{*}{$\begin{array}{l}\text { Tyler et al. } \\
\text { (2001) }\end{array}$} & \multirow{6}{*}{ PET } & \multirow{6}{*}{9} & \multirow{6}{*}{$\begin{array}{c}.05 \\
\text { corrected }\end{array}$} & \multirow{6}{*}{$\begin{array}{l}\text { Block } \\
\text { design }\end{array}$} & \multirow{2}{*}{ Lexical decision } & \multirow{2}{*}{ Letter detection task } & Verbs-Nouns & R substantia nigra \\
\hline & & & & & & & Nouns-Verbs & No area \\
\hline & & & & & \multirow{2}{*}{$\begin{array}{c}\text { Semantic } \\
\text { categorization task }\end{array}$} & \multirow{2}{*}{$\begin{array}{l}\text { Letter categorization } \\
\text { task }\end{array}$} & Verbs-Nouns & L BA 20/37 \\
\hline & & & & & & & Nouns-Verbs & No area \\
\hline & & & & & \multirow{2}{*}{\multicolumn{2}{|c|}{ Conjunction analysis }} & Verbs-Nouns & No area \\
\hline & & & & & & & Nouns-Verbs & No area \\
\hline \multirow[t]{2}{*}{$\begin{array}{l}\text { Tyler et al. } \\
\text { (2003) }\end{array}$} & \multirow[t]{2}{*}{ fMRI } & \multirow[t]{2}{*}{12} & \multirow{2}{*}{$\begin{array}{l}.001 \\
\text { uncorrected } \\
(.05 \text { at } \\
\text { cluster } \\
\text { level })\end{array}$} & \multirow[t]{2}{*}{$\begin{array}{l}\text { Event- } \\
\text { related }\end{array}$} & \multirow[t]{2}{*}{$\begin{array}{c}\text { Semantic } \\
\text { categorization task }\end{array}$} & \multirow[t]{2}{*}{$\begin{array}{l}\text { Letter categorization } \\
\text { task }\end{array}$} & Verbs(tools)-baseline & $\begin{array}{l}\text { L inf. Frontal gyrus, R ant. Cingulate gyrus, } \\
\text { L Fusiform and Parahippocampal gyrus, } \mathrm{L} \\
\text { Lingual gyrus, R inf. Frontal gyrus, R sup. } \\
\text { temporal gyrus, R Cerebellum. }\end{array}$ \\
\hline & & & & & & & $\begin{array}{l}\text { Verbs(biological)- } \\
\text { baseline }\end{array}$ & $\begin{array}{l}\text { L inf. Frontal gyrus, L sup. Temporal gyrus, } \\
\text { L Fusiform gyrus, L Parahippocampal } \\
\text { gyrus. L mid. Temporal gyrus, L inf. } \\
\text { Temporal gyrus, Cerebellum bilaterally }\end{array}$ \\
\hline
\end{tabular}


Table 1 (follows)

\begin{tabular}{|c|c|c|c|c|c|c|c|c|}
\hline Authors & Technique & $\begin{array}{c}\text { Sample } \\
\text { size }\end{array}$ & Threshold & Design & Experimental task & Baseline & Contrast & Area \\
\hline $\begin{array}{l}\text { Grossman et al. } \\
\qquad(2002)\end{array}$ & fMRI & 16 & $\begin{array}{c}.001 \\
\text { uncorrected }\end{array}$ & $\begin{array}{l}\text { Block } \\
\text { design }\end{array}$ & $\begin{array}{l}\text { Pleasantness } \\
\text { judgement }\end{array}$ & $\begin{array}{l}\text { Pseudoword passive } \\
\text { viewing }\end{array}$ & Verbs-baseline & $\begin{array}{l}\text { L postero-lateral Temporal cortex, } \\
\text { Bilateral ventral Temporo-Occipital } \\
\text { cortex, Bilateral Prefrontal cortex }\end{array}$ \\
\hline $\begin{array}{l}\text { Tyler et al. } \\
\text { (2004) }\end{array}$ & fMRI & 12 & $\begin{array}{c}.001 \\
\text { uncorrected } \\
(.05 \text { at cluster } \\
\text { level })\end{array}$ & $\begin{array}{l}\text { Event- } \\
\text { related }\end{array}$ & $\begin{array}{c}\text { Semantic } \\
\text { categorization task }\end{array}$ & $\begin{array}{l}\text { Letter } \\
\text { categorization task }\end{array}$ & Verbs-Nouns & L inf. Frontal gyrus \\
\hline \multirow{2}{*}{$\begin{array}{l}\text { Bedny et al. } \\
\qquad(2006)\end{array}$} & \multirow{2}{*}{ fMRI } & \multirow{2}{*}{13} & \multirow{2}{*}{.05 corrected } & \multirow{2}{*}{$\begin{array}{l}\text { Event- } \\
\text { related }\end{array}$} & \multirow{2}{*}{ Semantic matching } & \multirow{2}{*}{$\begin{array}{l}\text { Identity judgement } \\
\text { on pseudowords }\end{array}$} & Verbs-Nouns & L sup. Temporal gyrus, L post. Cingulate \\
\hline & & & & & & & Nouns-Verbs & $\begin{array}{l}\text { L inf. Frontal gyrus, } \\
\text { L inf. Temporal gyrus }\end{array}$ \\
\hline $\begin{array}{l}\text { Chao et al. } \\
\text { (2000) }\end{array}$ & fMRI & 10 & $\begin{array}{c}.001 \\
\text { uncorrected }\end{array}$ & $\begin{array}{l}\text { Block } \\
\text { design }\end{array}$ & Picture naming & $\begin{array}{l}\text { Passive viewing of } \\
\text { scrambled stimuli }\end{array}$ & Verbs-baseline & $\begin{array}{l}\text { L inf. Frontal gyrus, L insula, L ventral } \\
\text { Premotor cortex, L post. Parietal cortex }\end{array}$ \\
\hline $\begin{array}{l}\text { Damasio et al. } \\
\qquad(2001)\end{array}$ & PET & 20 & .05 corrected & $\begin{array}{l}\text { Block } \\
\text { design }\end{array}$ & Picture naming & $\begin{array}{l}\text { Orientation } \\
\text { judgement of } \\
\text { unknown faces }\end{array}$ & Verbs-baseline & $\begin{array}{l}\text { L Frontal operculum, L post. Mid. } \\
\text { Frontal gyrus, L infero-temporal, L and } \\
\text { R inf. Parietal lobule, L and R } \\
\text { supramarginal gyrus }\end{array}$ \\
\hline \multirow{2}{*}{$\begin{array}{l}\text { Tranel et al. } \\
\qquad(2005 \mathrm{a})\end{array}$} & \multirow[b]{2}{*}{ PET } & \multirow[b]{2}{*}{10} & \multirow[b]{2}{*}{.05 corrected } & \multirow{2}{*}{$\begin{array}{l}\text { Block } \\
\text { design }\end{array}$} & \multirow[b]{2}{*}{ Picture naming } & \multirow{2}{*}{$\begin{array}{l}\text { Passive viewing of } \\
\text { scrambled stimuli }\end{array}$} & Nouns(tools)-baseline & L post. lat. Infero-temporal \\
\hline & & & & & & & $\begin{array}{l}\text { Nouns(animals)- } \\
\text { baseline }\end{array}$ & L ant. ventral Infero-temporal \\
\hline \multirow{2}{*}{$\begin{array}{l}\text { Saccuman et al. } \\
\qquad(2006)\end{array}$} & \multirow[t]{2}{*}{ fMRI } & \multirow[t]{2}{*}{13} & \multirow{2}{*}{$\begin{array}{c}.001 \\
\text { uncorrected }\end{array}$} & \multirow{2}{*}{$\begin{array}{l}\text { Event- } \\
\text { related }\end{array}$} & \multirow[t]{2}{*}{ Picture naming } & \multirow[t]{2}{*}{ None } & Verbs-Nouns & $\begin{array}{l}\text { L intra-parietal sulcus, L Cerebellum, } \\
\text { R Fusiform gyrus }\end{array}$ \\
\hline & & & & & & & Nouns-Verbs & $\begin{array}{l}\text { R Cuneus, R post. Cingulate cortex, } \\
\text { R Caudate nucleus }\end{array}$ \\
\hline \multirow{3}{*}{$\begin{array}{l}\text { Tranel et al. } \\
\text { (2005b) }\end{array}$} & \multirow{3}{*}{ PET } & \multirow{3}{*}{10} & \multirow{3}{*}{.05 corrected } & \multirow{3}{*}{$\begin{array}{l}\text { Block } \\
\text { design }\end{array}$} & \multirow{3}{*}{ Picture naming } & \multirow{3}{*}{$\begin{array}{l}\text { Orientation } \\
\text { judgement on } \\
\text { unfamiliar faces }\end{array}$} & Nouns(tools)-baseline & L post. ventral Infero-temporal \\
\hline & & & & & & & Verbs-baseline & $\begin{array}{l}\text { L Frontal Operculum, L mid. Temporal, } \\
\text { L post. lat. infero-temporal }\end{array}$ \\
\hline & & & & & & & Verbs-Nouns(tools) & L mid. Temporal \\
\hline
\end{tabular}


Table 1 (end)

\begin{tabular}{|c|c|c|c|c|c|c|c|c|}
\hline Authors & Technique & $\begin{array}{l}\text { Sample } \\
\text { size }\end{array}$ & Threshold & Design & Experimental task & Baseline & Contrast & Area \\
\hline \multirow{4}{*}{$\begin{array}{l}\text { Shapiro et al. } \\
\qquad(2005)\end{array}$} & \multirow{4}{*}{ PET } & \multirow{4}{*}{12} & \multirow{4}{*}{$\begin{array}{c}.001 \\
\text { uncorrected }\end{array}$} & \multirow{4}{*}{$\begin{array}{l}\text { Block } \\
\text { design }\end{array}$} & \multirow{4}{*}{$\begin{array}{l}\text { Word and } \\
\text { pseudoword } \\
\text { inflection task }\end{array}$} & \multirow{4}{*}{$\begin{array}{l}\text { Pseudoword } \\
\text { reading }\end{array}$} & Verbs-Nouns & $\begin{array}{l}\text { L sup. Frontal gyrus, L inf. Frontal } \\
\text { gyrus, R cerebellum }\end{array}$ \\
\hline & & & & & & & Nouns-Verbs & $\begin{array}{l}\text { L Fusiform, R mid. sup. Temporal gyrus, } \\
\text { R Insula, R Cerebellum }\end{array}$ \\
\hline & & & & & & & $\begin{array}{l}\text { (Verbs-Nouns) and } \\
\text { (Pseudoverbs- } \\
\text { Pseudonouns) }\end{array}$ & L sup. Frontal gyrus \\
\hline & & & & & & & $\begin{array}{l}\text { (Nouns-Verbs) and } \\
\text { (Pseudonouns- } \\
\text { Pseudoverbs) }\end{array}$ & $\begin{array}{c}\text { R mid. sup. Temporal gyrus, L fusiform } \\
\text { gyrus }\end{array}$ \\
\hline \multirow{3}{*}{$\begin{array}{l}\text { Shapiro et al. } \\
\qquad(2006)\end{array}$} & \multirow{3}{*}{ fMRI } & \multirow{3}{*}{10} & .005 & \multirow{3}{*}{$\begin{array}{l}\text { Event- } \\
\text { related }\end{array}$} & \multirow{3}{*}{$\begin{array}{l}\text { Regular/irregular } \\
\text { abstract/concrete } \\
\text { word inflection }\end{array}$} & \multirow{3}{*}{ Fixation } & Nouns-Verbs & L Fusiform gyrus \\
\hline & & & 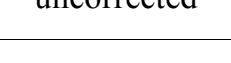 & & & & Verbs-Nouns & L Prefrontal cortex, L sup. parietal \\
\hline & & & .01 uncorrected & & & & $\begin{array}{l}\text { (Verbs-fixation) and } \\
\text { (Nouns-fixation) }\end{array}$ & $\begin{array}{c}\text { L inf. Premotor and Prefrontal cortex, L } \\
\text { mid. Temporal gyrus, L Temporo- } \\
\text { occipital junction }\end{array}$ \\
\hline
\end{tabular}


Table 2. Lexical-semantic variables for nouns and verbs in the GCST (mean \pm standard deviation).

\begin{tabular}{lcccc}
\hline Variable & Verbs $(n=45)$ & Nouns $(n=45)$ & tTest & $p$ \\
\hline Oral stem frequency & $36.53 \pm 77.66$ & $11.02 \pm 15.28$ & 2.16 & $<.05$ \\
Oral word surface frequency & $8.24 \pm 10.84$ & $8.10 \pm 16.23$ & .48 & n.s. \\
Imageability & $4.52 \pm 0.68$ & $4.30 \pm 0.92$ & 1.28 & n.s. \\
Number of letters & $8.06 \pm 1.54$ & $7.71 \pm 2.41$ & .24 & n.s. \\
Number of syllables & $3.47 \pm 0.59$ & $3.09 \pm 0.97$ & 2.23 & $<.05$ \\
Age of acquisition & $4.18 \pm 1.43$ & $3.77 \pm 1.31$ & -1.42 & n.s. \\
\hline
\end{tabular}


Table 3. Lexical-semantic variables for nouns and verbs in the PNT (mean \pm standard deviation)

\begin{tabular}{lcccc}
\hline Variable & Verbs $(n=45)$ & Nouns $(n=45)$ & $t$ Test & $p$ \\
\hline Oral stem frequency & $14.51 \pm 22.25$ & $8.02 \pm 15.28$ & 1.56 & n.s. \\
Oral word surface frequency & $6.66 \pm 12.02$ & $5.97 \pm 10.68$ & .25 & n.s. \\
Imageability & $4.74 \pm 0.70$ & $5.99 \pm 0.39$ & -10.46 & $<.001$ \\
Number of letters & $7.91 \pm 1.50$ & $6.91 \pm 1.74$ & 2.91 & $<.01$ \\
Number of syllables & $3.36 \pm 0.57$ & $2.91 \pm 0.76$ & 3.13 & $<.005$ \\
Age of acquisition & $3.62 \pm 1.17$ & $3.42 \pm 1.04$ & .85 & n.s. \\
Picture typicality & $5.59 \pm 0.81$ & $5.81 \pm 0.94$ & 1.29 & n.s. \\
Visual complexity & $4.18 \pm 1.28$ & $3.02 \pm 1.51$ & -4.69 & $<.001$ \\
\hline
\end{tabular}


Table 4. Behavioural results: mean reaction times (RTs, $m s)$ obtained by the participants in the three familiarization sessions.

\begin{tabular}{lccccc}
\hline & & Session 1 & Session 2 & Session 3 & Average \\
\cline { 3 - 6 } PNT & Nouns & 675 & 628 & 616 & 640 \\
& Verbs & 719 & 681 & 649 & 683 \\
& Nouns-Verbs & -44 & -53 & -33 & -43 \\
\hline \multirow{3}{*}{ GCST } & Nouns & 714 & 662 & 643 & 673 \\
& Verbs & 640 & 608 & 578 & 609 \\
& Nouns-Verbs & 74 & 54 & 65 & 64 \\
\hline
\end{tabular}


Table 5. Stepwise multiple regression analysis on the GCST RTs: standardized beta-coefficients, their corresponding $t$-values and their associated probability are reported, together with the partial correlation of each predictor with the dependent variable (inverse-transformed $R T$ s in the third familiarization session).

\begin{tabular}{lcccc}
\hline VARIABLES EXCLUDED FROM THE MODEL & Beta & $\mathrm{t}$-value & $\mathrm{p}$ & Partial correlation \\
\hline Number of Letters & -.13 & -1.22 & .22 & -.13 \\
Age of Acquisition & .01 & .07 & .94 & .01 \\
Imageability & -.04 & -.36 & .71 & .04 \\
Stem Frequency & -.13 & -1.25 & .21 & -.14 \\
& & & & \\
& Saturated model statistics: & $\mathrm{r}^{2}=.04$ & $\mathrm{~F}[4,82]=.78$ & $\mathrm{p}=.53$ \\
\hline
\end{tabular}


Table 6. Stepwise multiple regression analysis on the PNT RTs: standardized Beta coefficients, their corresponding $t$-values and their associated probability are reported, together with the partial correlation of each predictor with the dependent variable (inverse-transformed RTs in the third familiarization session).

\begin{tabular}{|c|c|c|c|c|}
\hline VARIABLES INCLUDED IN THE MODEL & Beta & t-value & $\mathrm{p}$ & Partial correlation \\
\hline Imageability & -.27 & -2.64 & .01 & -.27 \\
\hline VARIABLES EXCLUDED FROM THE MODEL & Beta & t-value & $\mathrm{p}$ & Partial correlation \\
\hline Age of Acquisition & .10 & .89 & .38 & .09 \\
\hline Number of Letters & .04 & .36 & .72 & -.12 \\
\hline Stem frequency & -.04 & -.37 & .71 & -.04 \\
\hline Model statistics: & $\mathrm{r}^{2}=.08$ & $\mathrm{~F}[1,87]=7.01$ & $\mathrm{p}=.01$ & \\
\hline
\end{tabular}


Table 7. Correlation matrix between the lexical-semantic variables considered. The $R$ coefficients obtained for the PNT stimuli are reported in normal typeface below the diagonal, while those calculated for the GCST stimuli are reported in italic above the diagonal. Significant values at $p<.05$ are indicated with an asterisk.

\begin{tabular}{lcccccc}
\hline & $\begin{array}{c}\text { Stem } \\
\text { frequency }\end{array}$ & $\begin{array}{c}\text { Surface } \\
\text { frequency }\end{array}$ & Letters & Syllables & $\begin{array}{c}\text { Age of } \\
\text { Acquisition }\end{array}$ & Imageability \\
\hline Stem Frequency & 1 & $.80^{*}$ & -.03 & -.10 & -.10 & -.14 \\
Surface Frequency & $.68^{*}$ & 1 & -.04 & -.14 & -.18 & -.12 \\
Number of Letters & .01 & -.13 & 1 & $.84^{*}$ & $.47^{*}$ & -.02 \\
Number of Syllables & -.06 & -.17 & $.83^{*}$ & 1 & $.51^{*}$ & -.04 \\
Age of Acquisition & -.16 & $-.34 *$ & .17 & .18 & 1 & $-.47^{*}$ \\
Imageability & -.19 & .01 & $-.23^{*}$ & $-.24^{*}$ & $-.37^{*}$ & 1 \\
\hline
\end{tabular}


Table 8. Brain regions of significant activation for the GCST (statistical threshold $=.001$

uncorrected; cluster size $\geq 20$; Talairach stereotactic coordinates are reported).

${ }^{\circ} Z$-score statistically significant also after the Family-wise Error (FWE) correction.

* Z-score statistically significant also after the False Discovery Rate (FDR) correction.

\begin{tabular}{|c|c|c|c|c|c|c|c|c|}
\hline \multirow{2}{*}{ Brain regions } & $\mathrm{x}$ & $\mathrm{y}$ & & Z score & $\mathrm{x}$ & & & Z score \\
\hline & \multicolumn{5}{|c|}{ Left hemisphere } & \multicolumn{3}{|c|}{ Right hemisphere } \\
\hline \multirow{3}{*}{ Middle Frontal gyrus } & & & & & & & & \\
\hline & -46 & 26 & 32 & $3.8^{*}$ & & & & \\
\hline & -48 & 26 & 36 & $3.8^{*}$ & & & & \\
\hline \multirow[t]{2}{*}{ Inferior Frontal gyrus pars Triangularis } & -48 & 28 & 0 & $4.8^{* \circ}$ & & & & \\
\hline & -48 & 16 & 30 & $4.2 * 0$ & & & & \\
\hline \multirow[t]{2}{*}{ Inferior Frontal gyrus pars Orbitalis } & -46 & 20 & -6 & $4.4^{*}$ & & & & \\
\hline & -44 & 28 & -2 & $4.6^{*}$ & & & & \\
\hline \multirow[t]{2}{*}{ Precentral gyrus } & -44 & 4 & 36 & $4.9 * \circ$ & & & & \\
\hline & -48 & 4 & 50 & $4.2^{*}$ & & & & \\
\hline Superior Temporal pole & -52 & 14 & -16 & $4.7 * 0$ & & & & \\
\hline \multirow[t]{2}{*}{ Inferior Temporal gyrus } & -54 & -48 & -18 & $4.9^{* \circ}$ & 56 & -40 & -18 & $3.5^{*}$ \\
\hline & -52 & -54 & -20 & $4.6^{*}$ & & & & \\
\hline Inferior Parietal lobule & -28 & -68 & 42 & $4.4^{*}$ & & & & \\
\hline \multirow[t]{2}{*}{ Superior Occipital gyrus } & -22 & -78 & 40 & $4.7 * \circ$ & 24 & -80 & 26 & $3.4^{*}$ \\
\hline & -24 & -80 & 32 & $4.6^{* \circ}$ & & & & \\
\hline \multirow[t]{2}{*}{ Middle Occipital gyrus } & -22 & -88 & 18 & $4.6^{*}$ & & & & \\
\hline & -24 & -86 & 22 & $4.6^{*}$ & & & & \\
\hline \multirow[t]{2}{*}{ Inferior Occipital gyrus } & -26 & -96 & -10 & $6.0^{* \circ}$ & 36 & -86 & -12 & $5.6^{* \circ}$ \\
\hline & -12 & -96 & -6 & $4.6^{*}$ & 24 & -100 & 0 & $6.5^{* \circ}$ \\
\hline \multirow[t]{2}{*}{ Lingual } & & & & & 24 & -90 & -12 & $5.7 * \circ$ \\
\hline & & & & & 28 & -92 & -12 & $5.6^{* \circ}$ \\
\hline Calcarine fissure & -14 & -92 & -4 & $4.7 * 0$ & 24 & -100 & 0 & $6.5^{* \circ}$ \\
\hline \multirow[t]{2}{*}{ Cerebellum } & -8 & -74 & -20 & $4.8^{* \circ}$ & 38 & -76 & -32 & $5.6^{* \circ}$ \\
\hline & -14 & -76 & -22 & $4.3^{*}$ & 36 & -64 & -32 & $5.7 * \circ$ \\
\hline
\end{tabular}


Table 8 (follows)

\begin{tabular}{|c|c|c|c|c|c|c|c|c|}
\hline \multirow{2}{*}{ Brain regions } & $\mathrm{x}$ & $\mathrm{y}$ & $\mathrm{Z}$ & Z score & $\mathrm{x}$ & & $\mathrm{Z}$ & Z score \\
\hline & \multicolumn{4}{|c|}{ Left hemisphere } & \multicolumn{4}{|c|}{ Right hemisphere } \\
\hline Verbs $>$ baseline & & & & & & & & \\
\hline \multirow[t]{2}{*}{ Precentral gyrus } & -50 & -2 & 50 & $3.5^{*}$ & 34 & -14 & 56 & $3.5^{*}$ \\
\hline & -46 & -4 & 38 & $4.0^{*}$ & & & & \\
\hline Supplementary Motor area & -8 & 8 & 50 & $3.7 *$ & & & & \\
\hline \multirow[t]{2}{*}{ Middle Cingulate gyrus } & -2 & -40 & 56 & $3.4^{*}$ & & & & \\
\hline & -4 & -8 & 38 & 3.2 & & & & \\
\hline Superior Temporal gyrus & -50 & -46 & 24 & $4.3^{*}$ & & & & \\
\hline Middle Temporal pole & & & & & 48 & 8 & -22 & $3.9^{*}$ \\
\hline \multirow[t]{2}{*}{ Middle Temporal gyrus } & -60 & -4 & -12 & $4.0^{*}$ & 54 & -6 & -18 & 3.2 \\
\hline & -58 & -52 & -2 & $4.1^{*}$ & 58 & 0 & -14 & 3.1 \\
\hline \multirow[t]{2}{*}{ Inferior Temporal gyrus } & -60 & -54 & -10 & $3.8^{*}$ & 56 & -42 & -16 & $3.5^{*}$ \\
\hline & -58 & -54 & -18 & $3.6^{*}$ & 36 & -90 & -10 & $3.4^{*}$ \\
\hline Supramarginal gyrus & -58 & -46 & 26 & $3.8^{*}$ & & & & \\
\hline \multirow[t]{2}{*}{ Angular gyrus } & -42 & -48 & 30 & $3.5^{*}$ & & & & \\
\hline & -36 & -50 & 34 & $3.6^{*}$ & & & & \\
\hline \multirow[t]{2}{*}{ Lingual gyrus } & -22 & -100 & -14 & 3.4 & 26 & -94 & -14 & $4.1^{*}$ \\
\hline & & & & & 26 & -88 & -16 & $4.0^{*}$ \\
\hline Inferior Occipital gyrus & & & & & 44 & -86 & -12 & $3.4^{*}$ \\
\hline Calcarine & & & & & 24 & -102 & 2 & $3.8^{*}$ \\
\hline \multirow[t]{2}{*}{ Cerebellum } & -40 & -54 & -32 & $5.0 * \circ$ & 36 & -72 & -30 & $3.5^{*}$ \\
\hline & -38 & -82 & -22 & $3.4 *$ & 34 & -68 & -28 & $3.5^{*}$ \\
\hline \multirow[t]{2}{*}{ Hippocampus } & -32 & -24 & -10 & $3.8^{*}$ & & & & \\
\hline & -32 & -18 & -16 & 3.3 & & & & \\
\hline
\end{tabular}


Table 8 (end)

\begin{tabular}{|c|c|c|c|c|c|c|c|c|}
\hline Brain regions & \multicolumn{4}{|c|}{ Left hemisphere } & \multicolumn{4}{|c|}{ Right hemisphere } \\
\hline Nouns $>$ Verbs & & & & & & & & \\
\hline \multirow[t]{2}{*}{ Inferior Frontal gyrus pars Triangularis } & -52 & 24 & 2 & 4.4 & & & & \\
\hline & -38 & 36 & 18 & 3.7 & & & & \\
\hline Inferior Frontal gyrus pars Orbitalis & -44 & 28 & -14 & 3.7 & & & & \\
\hline Inferior Parietal lobule & -46 & -46 & 62 & 3.2 & & & & \\
\hline Precuneus & -8 & -72 & 62 & 4.1 & & & & \\
\hline Middle Occipital gyrus & -24 & -88 & 16 & 3.4 & & & & \\
\hline Superior Occipital gyrus & -18 & -80 & 42 & 3.2 & & & & \\
\hline Cerebellum & -38 & -72 & -28 & 3.3 & 36 & -74 & -30 & 3.7 \\
\hline \multicolumn{9}{|l|}{ Verbs $>$ Nouns } \\
\hline Superior Frontal gyrus & -12 & 12 & 54 & $4.6^{*}$ & & & & \\
\hline \multirow[t]{2}{*}{ Precentral gyrus } & -26 & -18 & 62 & $3.8^{*}$ & 18 & -30 & 66 & $4.0^{*}$ \\
\hline & -32 & -24 & 58 & $3.6^{*}$ & 16 & -26 & 64 & $3.9 *$ \\
\hline \multirow[t]{2}{*}{ Supplementary motor area } & -6 & -12 & 64 & 3.2 & 4 & -20 & 58 & $4.5^{*}$ \\
\hline & & & & & 12 & -8 & 54 & 3.7 \\
\hline \multirow[t]{2}{*}{ Middle Cingulum } & -4 & -38 & 46 & 3.4 & 2 & -34 & 52 & 3.5 \\
\hline & -2 & -40 & 50 & 3.4 & & & & \\
\hline \multirow[t]{2}{*}{ Postcentral gyrus } & & & & & 16 & -34 & 64 & $4.2^{*}$ \\
\hline & & & & & 20 & -40 & 64 & $4.4^{*}$ \\
\hline Paracentral lobule & & & & & 6 & -32 & 56 & 3.5 \\
\hline \multirow[t]{2}{*}{ Precuneus } & & & & & 4 & -38 & 56 & 3.6 \\
\hline & & & & & 2 & -42 & 56 & 3.4 \\
\hline Parahippocampal gyrus & & & & & 16 & -2 & -16 & 3.6 \\
\hline Pallidum & & & & & 22 & -4 & 4 & 3.4 \\
\hline
\end{tabular}


Table 9. Brain regions of significant activation for the PNT contrasts (statistical threshold $=.001$ uncorrected; cluster size $\geq 20$; Talairach stereotactic coordinates are reported).

${ }^{\circ} Z$-score statistically significant also after the FWE correction.

* Z-score statistically significant also after the FDR correction.

\begin{tabular}{|c|c|c|c|c|c|c|c|c|}
\hline \multirow{2}{*}{ Brain regions } & $\mathrm{x}$ & $\mathrm{y}$ & $\mathrm{z}$ & Z score & $\bar{x}$ & $\mathrm{y}$ & $\mathrm{z}$ & Z score \\
\hline & \multicolumn{4}{|c|}{ Left hemisphere } & \multicolumn{4}{|c|}{ Right hemisphere } \\
\hline \multicolumn{9}{|l|}{ Nouns $>$ baseline } \\
\hline Inferior temporal gyrus & & & & & 50 & -64 & -18 & $5.6^{* \circ}$ \\
\hline Superior Occipital gyrus & -22 & -92 & 34 & $3.2^{*}$ & & & & \\
\hline \multirow[t]{2}{*}{ Inferior Occipital gyrus } & -44 & -78 & -8 & $6.6^{* \circ}$ & 36 & -92 & 0 & $5.0^{* \circ}$ \\
\hline & & & & & 48 & -82 & -2 & $6.6^{* \circ}$ \\
\hline \multirow[t]{2}{*}{ Cerebellum } & -38 & -54 & -28 & $5.7 * \circ$ & 44 & -50 & -26 & $4.5^{*}$ \\
\hline & & & & & 40 & -50 & -32 & $5.2 * \circ$ \\
\hline \multicolumn{9}{|l|}{ Verbs $>$ baseline } \\
\hline \multirow[t]{2}{*}{ Inferior Frontal gyrus pars triangularis } & -54 & 30 & 20 & $3.5^{*}$ & & & & \\
\hline & -50 & 26 & 32 & $3.1^{*}$ & & & & \\
\hline Inferior Temporal gyrus & & & & & 52 & -66 & -12 & $6.7 * \circ$ \\
\hline Cuneus & & & & & 16 & -86 & 46 & $3.2^{*}$ \\
\hline \multirow[t]{2}{*}{ Superior Occipital gyrus } & -24 & -88 & 28 & $6.1 * \circ$ & 28 & -88 & 28 & $5.0^{* \circ}$ \\
\hline & -26 & -88 & 24 & $5.9 * \circ$ & & & & \\
\hline \multirow[t]{2}{*}{ Middle Occipital gyrus } & -32 & -90 & 16 & $5.4 * \circ$ & 36 & -92 & 4 & $6.5^{* \circ}$ \\
\hline & -34 & -94 & 8 & $5.3^{* \circ}$ & 34 & -88 & 16 & $6.2 * \circ$ \\
\hline Calcarine & -10 & -78 & 6 & $4.3^{*}$ & & & & \\
\hline \multirow[t]{2}{*}{ Inferior Occipital gyrus } & -46 & -74 & -8 & $7.4 * \circ$ & 48 & -80 & -2 & $7.5 * \circ$ \\
\hline & -52 & -72 & -2 & $7.3 * \circ$ & 52 & -66 & -12 & $6.7 * \circ$ \\
\hline Fusiform gyrus & -24 & -74 & -8 & $4.6^{* \circ}$ & & & & \\
\hline \multirow[t]{2}{*}{ Lingual gyrus } & -8 & -74 & 6 & $4.3^{*}$ & 10 & -58 & 0 & $4.0^{*}$ \\
\hline & -12 & -62 & -2 & $3.5^{*}$ & 38 & -46 & -32 & $6.8^{* \circ}$ \\
\hline \multirow[t]{2}{*}{ Cerebellum } & -42 & -62 & -22 & $7.1 * \circ$ & 40 & -64 & -22 & $5.9 * \circ$ \\
\hline & -44 & -54 & -26 & 6.7 & & & & \\
\hline Hippocampus & & & & & 22 & -32 & -4 & $4.4^{*}$ \\
\hline Parahippocampal gyrus & -18 & -34 & -8 & $3.8^{*}$ & & & & \\
\hline
\end{tabular}


Table 9 (follows)

\begin{tabular}{|c|c|c|c|c|c|c|c|c|}
\hline Brain regions & \multicolumn{4}{|c|}{ Left hemisphere } & \multicolumn{4}{|c|}{ Right hemisphere } \\
\hline Verbs $>$ Nouns & & & & & & & & \\
\hline Inferior Frontal gyrus & -36 & 22 & 2 & $4.0^{*}$ & & & & \\
\hline Insula & -32 & 20 & 2 & $3.9^{*}$ & & & & \\
\hline \multirow[t]{2}{*}{ Paracentral lobule } & -10 & -38 & 72 & $3.4^{*}$ & & & & \\
\hline & & & & & 8 & -36 & 66 & $3.4^{*}$ \\
\hline Superior Parietal lobule & & & & & 26 & -56 & 60 & $3.8^{*}$ \\
\hline \multirow[t]{2}{*}{ Precuneus } & -12 & -46 & 74 & $3.3^{*}$ & 10 & -42 & 60 & $3.6^{*}$ \\
\hline & -10 & -50 & 66 & $3.3^{*}$ & & & & \\
\hline \multirow[t]{2}{*}{ Middle Temporal gyrus } & -58 & -50 & 6 & $4.2 *$ & 52 & -76 & 8 & $6.1 * \circ$ \\
\hline & & & & & 52 & -66 & 0 & $5.7 * \circ$ \\
\hline Inferior Temporal gyrus & & & & & 48 & -34 & -20 & $3.5^{*}$ \\
\hline \multirow[t]{2}{*}{ Superior Occipital gyrus } & -20 & -80 & 28 & $3.2 *$ & 24 & -90 & 34 & $4.2 *$ \\
\hline & & & & & 22 & -94 & 26 & $3.5^{*}$ \\
\hline Middle Occipital gyrus & -50 & -72 & 6 & $6.0 * \circ$ & 38 & -86 & 6 & $4.4^{*}$ \\
\hline \multirow[t]{2}{*}{ Calcarine } & -10 & -100 & -12 & $3.5^{*}$ & 16 & -90 & 4 & $4.3^{*}$ \\
\hline & & & & & 12 & -92 & 12 & $3.4^{*}$ \\
\hline \multirow[t]{2}{*}{ Lingual gyrus } & -12 & -82 & -6 & $3.6^{*}$ & & & & \\
\hline & -6 & -70 & 6 & $3.4^{*}$ & & & & \\
\hline \multirow[t]{2}{*}{ Cerebellum } & -34 & -36 & -32 & $3.7^{*}$ & 44 & -44 & -28 & $4.7 * \circ$ \\
\hline & -46 & -54 & -26 & $3.4^{*}$ & 22 & -74 & -16 & $4.4^{*}$ \\
\hline Putamen & -28 & 14 & -2 & $4.0^{*}$ & & & & \\
\hline Hippocampus & -14 & -2 & -14 & $3.6^{*}$ & & & & \\
\hline
\end{tabular}


Table 10. Brain regions showing activation for the verbs-minus-nouns comparison in both the PNT and the GCST (statistical threshold $=.05$ uncorrected; cluster size $\geq 20$; Talairach stereotactic coordinates are reported).

${ }^{\circ} Z$-score statistically significant also after the FWE correction.

* Z-score statistically significant also after the FDR correction.

\begin{tabular}{|c|c|c|c|c|c|c|c|c|}
\hline \multirow{2}{*}{ Brain regions } & $\mathrm{x}$ & $\mathrm{y}$ & $\mathrm{z}$ & Z score & $\mathrm{x}$ & $\mathrm{y}$ & $\mathrm{z}$ & $Z$ score \\
\hline & \multicolumn{4}{|c|}{ Left hemisphere } & \multicolumn{4}{|c|}{ Right hemisphere } \\
\hline \multirow[t]{2}{*}{ Precentral gyrus } & -40 & -24 & 60 & $4.5^{*}$ & 38 & -26 & 58 & $4.2 *$ \\
\hline & -22 & -18 & 62 & $4.4^{*}$ & & & & \\
\hline Supplementary Motor area & & & & & 4 & -8 & 58 & $4.0^{*}$ \\
\hline \multirow[t]{2}{*}{ Postcentral gyrus } & -32 & -24 & 46 & $4.9^{* \circ}$ & 26 & -46 & 64 & $5.0^{* \circ}$ \\
\hline & -38 & -34 & 58 & $4.6^{*}$ & 16 & -30 & 60 & $4.4 *$ \\
\hline \multirow[t]{2}{*}{ Paracentral lobule } & -14 & -34 & 74 & $4.2^{*}$ & 10 & -36 & 64 & $5.0^{* \circ}$ \\
\hline & -8 & -22 & 58 & $4.7^{*}$ & & & & \\
\hline \multirow[t]{2}{*}{ Superior Parietal lobule } & -18 & -56 & 60 & $4.3^{*}$ & 18 & -44 & 70 & $4.9^{* \circ}$ \\
\hline & & & & & 16 & -42 & 64 & $5.4^{* \circ}$ \\
\hline \multirow[t]{2}{*}{ Precuneus } & -14 & -44 & 66 & $4.3^{*}$ & 10 & -42 & 64 & $5.1 * \circ$ \\
\hline & -12 & -40 & 68 & $4.3^{*}$ & 6 & -40 & 60 & $5.2 * 0$ \\
\hline Inferior Parietal lobule & & & & & 32 & -46 & 56 & $4.2^{*}$ \\
\hline Hippocampus & -14 & -4 & -16 & $4.2^{*}$ & & & & \\
\hline Amygdala & & & & & 18 & 0 & -14 & $4.8^{* \circ}$ \\
\hline Thalamus & -18 & -28 & 10 & $4.0^{*}$ & & & & \\
\hline
\end{tabular}


Table 11. Brain regions showing activation for the verbs-minus-nouns comparison in the PNT and the nouns-minus-verbs comparison in the GCST (statistical threshold $=.05$ uncorrected; cluster size $\geq 20$; Talairach stereotactic coordinates are reported).

${ }^{\circ} Z$-score statistically significant also after the FWE correction.

* Z-score statistically significant also after the FDR correction.

\begin{tabular}{|l|cccccccc|}
\hline \multicolumn{1}{|c|}{ Brain regions } & $\mathrm{x}$ & $\mathrm{y}$ & $\mathrm{z}$ & $\mathrm{Z}$ score & $\mathrm{x}$ & $\mathrm{y}$ & $\mathrm{z}$ & $\mathrm{Z}$ score \\
Left hemisphere & & \multicolumn{5}{c|}{ Right hemisphere } \\
\hline Inferior Frontal gyrus pars Triangularis & -52 & 32 & 14 & 2.9 & & & & \\
& -48 & 24 & 22 & 2.6 & & & & \\
Insula & -30 & 22 & -2 & 2.6 & & & & \\
Inferior Temporal gyrus & -54 & -56 & -16 & 2.6 & & & & \\
Superior Occipital gyrus & -48 & -50 & -18 & 2.3 & & & & \\
Middle Occipital gyrus & -24 & -86 & 28 & $5.0^{* \circ}$ & 26 & -80 & 30 & $3.9^{*}$ \\
& -26 & -88 & 20 & $5.2^{* \circ}$ & 32 & -88 & 14 & $4.2^{*}$ \\
Cerebellum & -28 & -94 & 10 & $4.0^{*}$ & 38 & -74 & 10 & 2.8 \\
& -12 & -78 & -16 & $4.0^{*}$ & 10 & -70 & -34 & $3.9^{*}$ \\
& -38 & -74 & -18 & 2.8 & 10 & -78 & -18 & $3.6^{*}$ \\
\hline
\end{tabular}


Appendix A: list of the stimuli entering the GCST.

$G C=$ grammatical class; Conj = conjugation; Stem freq = oral stem frequency; Surf freq = oral surface frequency; Let = number of letters; Syl = number of syllables; AoA = Age of acquisition; Imag = imageability.

\begin{tabular}{|c|c|c|c|c|c|c|c|c|c|c|}
\hline $\mathbf{N}$ & Item & & GC & Conj & Stem freq & Surf freq & Let & Syl & $\operatorname{AoA}$ & Imag \\
\hline 1 & abbracciare & to embrace & verb & 1 & 17 & 1 & 11 & 4 & 3.1 & 5.0 \\
\hline 2 & arrestare & to arrest & verb & 1 & 9 & 0 & 9 & 4 & 5.0 & 4.0 \\
\hline 3 & baciare & to kiss & verb & 1 & 1 & 1 & 7 & 3 & 2.8 & 6.1 \\
\hline 4 & ballare & to dance & verb & 1 & 17 & 7 & 7 & 3 & 3.1 & 4.9 \\
\hline 5 & bombardare & to bomb & verb & 1 & 0 & 0 & 10 & 4 & 6.1 & 4.0 \\
\hline 6 & calcolare & to calculate & verb & 1 & 11 & 3 & 9 & 4 & 4.8 & 4.3 \\
\hline 7 & camminare & to walk & verb & 1 & 18 & 6 & 9 & 4 & 2.3 & 5.1 \\
\hline 8 & cantare & to sing & verb & 1 & 11 & 4 & 7 & 3 & 2.5 & 4.5 \\
\hline 9 & conversare & to converse & verb & 1 & 1 & 1 & 10 & 4 & 6.4 & 4.5 \\
\hline 10 & crollare & to collapse & verb & 1 & 8 & 2 & 8 & 3 & 5.6 & 4.2 \\
\hline 11 & giurare & to swear & verb & 1 & 22 & 2 & 7 & 3 & 4.9 & 3.2 \\
\hline 12 & interrogare & to examine & verb & 1 & 15 & 2 & 11 & 5 & 5.1 & 4.7 \\
\hline 13 & lanciare & to throw & verb & 1 & 22 & 2 & 8 & 3 & 3.5 & 4.3 \\
\hline 14 & massaggiare & to massage & verb & 1 & 0 & 0 & 11 & 4 & 5.6 & 4.6 \\
\hline 15 & nevicare & to snow & verb & 1 & 4 & 0 & 8 & 4 & 2.9 & 5.7 \\
\hline 16 & pattinare & to skate & verb & 1 & 0 & 0 & 9 & 4 & 4.0 & 5.3 \\
\hline 17 & potare & to prune & verb & 1 & 7 & 0 & 6 & 3 & 6.8 & 3.7 \\
\hline 18 & pregare & to pray & verb & 1 & 41 & 3 & 7 & 3 & 3.5 & 4.6 \\
\hline 19 & saltare & to jump & verb & 1 & 22 & 2 & 7 & 3 & 2.3 & 4.5 \\
\hline 20 & salutare & to greet & verb & 1 & 111 & 9 & 8 & 4 & 1.4 & 5.1 \\
\hline 21 & salvare & to save & verb & 1 & 22 & 9 & 7 & 3 & 4.5 & 2.6 \\
\hline 22 & sbadigliare & to yawn & verb & 1 & 1 & 1 & 11 & 4 & 3.6 & 5.2 \\
\hline 23 & scoppiare & to burst & verb & 1 & 9 & 1 & 9 & 3 & 4.2 & 4.1 \\
\hline 24 & soffiare & to puff & verb & 1 & 9 & 0 & 8 & 3 & 2.7 & 4.2 \\
\hline 25 & sparare & to shoot & verb & 1 & 9 & 2 & 7 & 3 & 4.2 & 4.9 \\
\hline 26 & ululare & to howl & verb & 1 & 0 & 0 & 7 & 4 & 5.2 & 4.0 \\
\hline 27 & volare & to fly & verb & 1 & 17 & 9 & 6 & 3 & 2.4 & 4.1 \\
\hline 28 & cadere & to fall & verb & 2 & 62 & 19 & 6 & 3 & 2.3 & 4.6 \\
\hline 29 & correre & to run & verb & 2 & 29 & 3 & 7 & 3 & 2.5 & 5.3 \\
\hline 30 & esplodere & to explode & verb & 2 & 7 & 2 & 9 & 4 & 5.1 & 4.5 \\
\hline 31 & evadere & to escape & verb & 2 & 0 & 0 & 7 & 4 & 6.6 & 3.2 \\
\hline 32 & leggere & to read & verb & 2 & 263 & 67 & 7 & 3 & 3.4 & 4.8 \\
\hline 33 & mordere & to bite & verb & 2 & 0 & 0 & 7 & 3 & 3.3 & 5.0 \\
\hline 34 & nascere & to be born & verb & 2 & 94 & 7 & 7 & 3 & 3.4 & 3.6 \\
\hline
\end{tabular}




\begin{tabular}{|c|c|c|c|c|c|c|c|c|c|c|}
\hline 35 & piangere & to cry & verb & 2 & 24 & 7 & 8 & 3 & 1.9 & 4.4 \\
\hline 36 & piovere & to rain & verb & 2 & 10 & 0 & 7 & 3 & 2.4 & 5.3 \\
\hline 37 & raccogliere & to harvest & verb & 2 & 39 & 6 & 11 & 4 & 3.2 & 4.0 \\
\hline 38 & radere & to shave & verb & 2 & 3 & 0 & 6 & 3 & 6.6 & 4.5 \\
\hline 39 & ridere & to laugh & verb & 2 & 41 & 22 & 6 & 3 & 1.8 & 5.5 \\
\hline 40 & scrivere & to write & verb & 2 & 420 & 57 & 8 & 3 & 3.2 & 5.0 \\
\hline 41 & applaudire & to applaud & verb & 3 & 2 & 2 & 10 & 5 & 4.7 & 5.1 \\
\hline 42 & costruire & to build & verb & 3 & 39 & 16 & 9 & 4 & 3.3 & 3.9 \\
\hline 43 & partire & to leave & verb & 3 & 207 & 62 & 7 & 3 & 3.9 & 4.2 \\
\hline 44 & ruggire & to roar & verb & 3 & 0 & 0 & 7 & 3 & 5.0 & 4.2 \\
\hline 45 & starnutire & to sneeze & verb & 3 & 0 & 0 & 10 & 4 & 4.2 & 5.0 \\
\hline 46 & abbraccio & embrace & noun & & 15 & 13 & 9 & 3 & 2.7 & 6.0 \\
\hline 47 & applauso & applause & noun & & 10 & 6 & 8 & 4 & 4.2 & 4.9 \\
\hline 48 & arresto & arrest & noun & & 0 & 0 & 7 & 3 & 5.6 & 3.0 \\
\hline 49 & bacio & kiss & noun & & 61 & 19 & 5 & 2 & 1.8 & 6.0 \\
\hline 50 & ballo & dance & noun & & 5 & 5 & 5 & 2 & 3.0 & 5.8 \\
\hline 51 & bombardamento & bombardment & noun & & 3 & 2 & 13 & 5 & 6.2 & 4.5 \\
\hline 52 & caduta & fall & noun & & 5 & 4 & 6 & 3 & 2.7 & 4.0 \\
\hline 53 & calcolo & calculation & noun & & 32 & 12 & 7 & 3 & 5.8 & 2.5 \\
\hline 54 & camminata & walk & noun & & 0 & 0 & 9 & 4 & 4.5 & 4.5 \\
\hline 55 & canto & song & noun & & 10 & 10 & 5 & 2 & 2.6 & 4.7 \\
\hline 56 & conversazione & conversation & noun & & 10 & 10 & 13 & 5 & 6.9 & 4.1 \\
\hline 57 & corsa & run & noun & & 8 & 7 & 5 & 2 & 2.8 & 4.2 \\
\hline 58 & costruzione & construction & noun & & 34 & 27 & 11 & 4 & 3.7 & 3.9 \\
\hline 59 & crollo & collapse & noun & & 2 & 2 & 6 & 2 & 5.6 & 4.2 \\
\hline 60 & esplosione & explosion & noun & & 3 & 3 & 10 & 4 & 5.3 & 5.0 \\
\hline 61 & evasione & escape & noun & & 4 & 4 & 8 & 4 & 6.5 & 3.0 \\
\hline 62 & giuramento & oath & noun & & 8 & 7 & 10 & 4 & 5.8 & 2.8 \\
\hline 63 & interrogazione & interrogation & noun & & 12 & 6 & 15 & 6 & 5.8 & 4.4 \\
\hline 64 & lancio & throw & noun & & 0 & 0 & 6 & 2 & 3.8 & 3.8 \\
\hline 65 & lettura & reading & noun & & 64 & 54 & 7 & 3 & 4.2 & 3.4 \\
\hline 66 & massaggio & massage & noun & & 0 & 0 & 9 & 3 & 5.2 & 5.1 \\
\hline 67 & morso & bite & noun & & 5 & 4 & 5 & 2 & 2.2 & 4.1 \\
\hline 68 & nascita & birth & noun & & 34 & 33 & 7 & 3 & 3.9 & 5.3 \\
\hline 69 & nevicata & snow & noun & & 14 & 14 & 6 & 3 & 2.2 & 6.2 \\
\hline 70 & partenza & departure & noun & & 15 & 15 & 8 & 3 & 3.8 & 3.2 \\
\hline 71 & pattinaggio & skating & noun & & 0 & 0 & 11 & 4 & 4.5 & 4.5 \\
\hline 72 & pianto & crying & noun & & 1 & 1 & 6 & 2 & 2.2 & 4.7 \\
\hline 73 & pioggia & rain & noun & & 25 & 14 & 7 & 2 & 2.4 & 6.2 \\
\hline 74 & potatura & pruning & noun & & 0 & 0 & 8 & 4 & 7.1 & 3.8 \\
\hline 75 & preghiera & prayer & noun & & 12 & 8 & 9 & 3 & 3.1 & 3.1 \\
\hline
\end{tabular}




\begin{tabular}{llllcccccc}
76 & raccolta & harvest & noun & 19 & 17 & 8 & 3 & 4.6 & 3.0 \\
77 & rasatura & shaving & noun & 0 & 0 & 8 & 4 & 6.5 & 3.8 \\
78 & risata & laugh & noun & 4 & 1 & 6 & 3 & 3.5 & 4.3 \\
79 & ruggito & roar & noun & 0 & 0 & 7 & 3 & 4.7 & 4.2 \\
80 & salto & jump & noun & 11 & 9 & 5 & 2 & 2.4 & 4.0 \\
81 & saluto & greeting & noun & 41 & 23 & 6 & 3 & 2.5 & 4.6 \\
82 & salvataggio & rescue & noun & 0 & 0 & 11 & 4 & 5.5 & 4.2 \\
83 & sbadiglio & yawn & noun & 0 & 0 & 9 & 3 & 3.4 & 5.3 \\
84 & scoppio & burst & noun & 4 & 4 & 7 & 2 & 4.8 & 4.2 \\
85 & scrittura & writing & noun & 11 & 10 & 9 & 3 & 3.9 & 4.1 \\
86 & soffio & puff & noun & 0 & 0 & 6 & 2 & 3.5 & 2.9 \\
87 & sparo & shot & noun & 0 & 0 & 5 & 2 & 4.1 & 4.0 \\
88 & starnuto & sneeze & noun & 0 & 0 & 8 & 3 & 4.1 & 5.4 \\
89 & ululato & howl & noun & 1 & 1 & 7 & 4 & 5.4 & 4.2 \\
90 & volo & flight & noun & 13 & 11 & 4 & 2 & 3.2 & 4.8 \\
\hline
\end{tabular}


Appendix B: list of the stimuli entering the PNT.

$G C=$ grammatical class; Conj $=$ conjugation; Stem freq $=$ oral stem frequency; Surf freq $=$ oral surface frequency; Let = number of letters; Syl = number of syllables; AoA = Age of acquisition; Imag = imageability.

\begin{tabular}{|c|c|c|c|c|c|c|c|c|c|c|}
\hline $\mathbf{N}$ & Item & & GC & Conj & Stem freq & Surf freq & Let & Syl & AoA & Imag \\
\hline 1 & accarezzare & to caress & verb & 1 & 2 & 2 & 11 & 5 & 2.7 & 5.6 \\
\hline 2 & affogare & to drown & verb & 1 & 1 & 1 & 8 & 4 & 4.3 & 4.3 \\
\hline 3 & affondare & to $\sin k$ & verb & 1 & 2 & 2 & 9 & 4 & 5.1 & 3.9 \\
\hline 4 & annaffiare & to water & verb & 1 & 0 & 0 & 10 & 4 & 4.1 & 4.9 \\
\hline 5 & atterrare & to land & verb & 1 & 1 & 1 & 9 & 4 & 5.9 & 3.9 \\
\hline 6 & baciare & to kiss & verb & 1 & 1 & 1 & 7 & 3 & 2.5 & 5.5 \\
\hline 7 & brillare & to shine & verb & 1 & 1 & 1 & 8 & 3 & 4.8 & 3.6 \\
\hline 8 & bussare & to knock & verb & 1 & 0 & 0 & 7 & 3 & 3.4 & 5.4 \\
\hline 9 & camminare & to walk & verb & 1 & 18 & 6 & 9 & 4 & 2.1 & 5.8 \\
\hline 10 & decollare & to take off & verb & 1 & 1 & 1 & 9 & 4 & 6.0 & 4.4 \\
\hline 11 & fischiare & to hiss & verb & 1 & 3 & 1 & 9 & 3 & 3.8 & 4.5 \\
\hline 12 & gonfiare & to swell & verb & 1 & 7 & 0 & 8 & 3 & 4.0 & 4.4 \\
\hline 13 & guidare & to guide/drive & verb & 1 & 14 & 2 & 7 & 3 & 4.6 & 5.6 \\
\hline 14 & imbucare & to post & verb & 1 & 6 & 0 & 8 & 4 & 5.7 & 3.9 \\
\hline 15 & lanciare & to launch & verb & 1 & 22 & 2 & 8 & 3 & 3.2 & 4.5 \\
\hline 16 & leccare & to lick & verb & 1 & 0 & 0 & 7 & 3 & 2.9 & 4.4 \\
\hline 17 & legare & to tie & verb & 1 & 40 & 1 & 6 & 3 & 3.6 & 4.5 \\
\hline 18 & marciare & to march & verb & 1 & 4 & 1 & 8 & 3 & 5.5 & 4.3 \\
\hline 19 & nuotare & to swim & verb & 1 & 0 & 0 & 7 & 3 & 3.9 & 5.9 \\
\hline 20 & pattinare & to skate & verb & 1 & 0 & 0 & 9 & 4 & 4.5 & 5.2 \\
\hline 21 & pelare & to peel & verb & 1 & 0 & 0 & 6 & 3 & 5.0 & 3.9 \\
\hline 22 & pregare & to pray & verb & 1 & 41 & 3 & 7 & 3 & 4.5 & 5.9 \\
\hline 23 & salutare & to greet & verb & 1 & 111 & 9 & 8 & 4 & 1.8 & 5.4 \\
\hline 24 & sanguinare & to bleed & verb & 1 & 1 & 1 & 10 & 4 & 4.1 & 4.5 \\
\hline 25 & sbadigliare & to yawn & verb & 1 & 1 & 1 & 11 & 4 & 3.5 & 5.7 \\
\hline 26 & sciare & to ski & verb & 1 & 0 & 0 & 6 & 3 & 4.4 & 5.5 \\
\hline 27 & scivolare & to slip & verb & 1 & 14 & 8 & 9 & 4 & 2.9 & 4.5 \\
\hline 28 & soffiare & to blow & verb & 1 & 9 & 0 & 8 & 3 & 2.4 & 5.3 \\
\hline 29 & sollevare & to raise & verb & 1 & 3 & 2 & 9 & 4 & 4.4 & 4.3 \\
\hline 30 & sparare & to shoot & verb & 1 & 9 & 2 & 7 & 3 & 4.2 & 4.3 \\
\hline 31 & tagliare & to cut & verb & 1 & 39 & 14 & 8 & 3 & 3.0 & 5.0 \\
\hline 32 & volare & to fly & verb & 1 & 17 & 9 & 6 & 3 & 2.9 & 4.4 \\
\hline 33 & bere & to drink & verb & 2 & 18 & 8 & 4 & 2 & 1.6 & 5.7 \\
\hline
\end{tabular}




\begin{tabular}{|c|c|c|c|c|c|c|c|c|c|c|}
\hline 34 & cadere & to fall & verb & 2 & 62 & 19 & 6 & 3 & 1.8 & 4.3 \\
\hline 35 & mordere & to bite & verb & 2 & 0 & 0 & 7 & 3 & 2.6 & 5.1 \\
\hline 36 & piangere & to cry & verb & 2 & 24 & 7 & 8 & 3 & 1.8 & 5.1 \\
\hline 37 & raccogliere & to collect & verb & 2 & 39 & 6 & 11 & 4 & 3.9 & 4.2 \\
\hline 38 & ridere & to laugh & verb & 2 & 41 & 22 & 6 & 3 & 2.3 & 5.6 \\
\hline 39 & scendere & to descend & verb & 2 & 44 & 12 & 8 & 3 & 2.6 & 4.2 \\
\hline 40 & scrivere & to write & verb & 2 & 420 & 57 & 8 & 3 & 3.5 & 5.6 \\
\hline 41 & scuotere & to shake & verb & 2 & 0 & 0 & 8 & 3 & 5.5 & 3.7 \\
\hline 42 & spingere & to push & verb & 2 & 13 & 2 & 8 & 3 & 3.2 & 4.2 \\
\hline 43 & ruggire & to roar & verb & 3 & 0 & 0 & 7 & 3 & 4.2 & 3.4 \\
\hline 44 & salire & to go up & verb & 3 & 35 & 10 & 6 & 3 & 2.9 & 4.2 \\
\hline 45 & starnutire & to sneeze & verb & 3 & 0 & 0 & 10 & 4 & 2.9 & 4.8 \\
\hline 46 & ananas & pineapple & noun & & 1 & 1 & 6 & 3 & 4.5 & 6.4 \\
\hline 47 & arpa & harp & noun & & 2 & 2 & 4 & 2 & 5.7 & 5.5 \\
\hline 48 & banana & banana & noun & & 0 & 0 & 6 & 3 & 2.3 & 6.3 \\
\hline 49 & bottiglia & bottle & noun & & 11 & 8 & 9 & 3 & 1.9 & 6.6 \\
\hline 50 & camion & truck & noun & & 12 & 12 & 6 & 2 & 3.1 & 6.0 \\
\hline 51 & cammello & camel & noun & & 0 & 0 & 8 & 3 & 3.9 & 5.7 \\
\hline 52 & candela & candle & noun & & 0 & 0 & 7 & 3 & 2.7 & 6.5 \\
\hline 53 & cane & $\operatorname{dog}$ & noun & & 59 & 39 & 4 & 2 & 1.9 & 6.2 \\
\hline 54 & canguro & kangaroo & noun & & 0 & 0 & 7 & 3 & 3.9 & 5.6 \\
\hline 55 & carota & carrot & noun & & 4 & 2 & 6 & 3 & 2.9 & 6.2 \\
\hline 56 & cavallo & horse & noun & & 43 & 37 & 7 & 3 & 2.6 & 6.2 \\
\hline 57 & chiesa & church & noun & & 34 & 30 & 6 & 2 & 2.9 & 6.2 \\
\hline 58 & chitarra & guitar & noun & & 3 & 3 & 8 & 3 & 4.3 & 6.5 \\
\hline 59 & ciliegia & cherry & noun & & 0 & 0 & 8 & 3 & 2.9 & 6.5 \\
\hline 60 & clessidra & hourglass & noun & & 0 & 0 & 9 & 3 & 6.1 & 5.9 \\
\hline 61 & coltello & knife & noun & & 2 & 2 & 8 & 3 & 2.3 & 6.5 \\
\hline 62 & cravatta & necktie & noun & & 2 & 2 & 8 & 3 & 3.9 & 6.3 \\
\hline 63 & cucchiaio & spoon & noun & & 7 & 7 & 9 & 3 & 2.0 & 6.5 \\
\hline 64 & damigiana & demijohn & noun & & 0 & 0 & 9 & 4 & 4.9 & 5.1 \\
\hline 65 & divano & sofa & noun & & 36 & 32 & 6 & 3 & 2.5 & 6.5 \\
\hline 66 & elefante & elephant & noun & & 1 & 1 & 8 & 4 & 2.7 & 6.2 \\
\hline 67 & fionda & sling & noun & & 0 & 0 & 6 & 2 & 4.4 & 5.2 \\
\hline 68 & fragola & strawberry & noun & & 0 & 0 & 7 & 3 & 2.5 & 6.5 \\
\hline 69 & giacca & jacket & noun & & 9 & 5 & 6 & 2 & 3.3 & 6.1 \\
\hline 70 & giraffa & giraffe & noun & & 0 & 0 & 7 & 3 & 2.9 & 5.7 \\
\hline 71 & guanto & glove & noun & & 0 & 0 & 6 & 2 & 2.9 & 6.3 \\
\hline 72 & gufo & owl & noun & & 0 & 0 & 4 & 2 & 4.1 & 5.5 \\
\hline 73 & imbuto & funnel & noun & & 0 & 0 & 6 & 3 & 3.8 & 5.9 \\
\hline 74 & ippopotamo & hippopotamus & noun & & 1 & 1 & 10 & 5 & 4.0 & 5.7 \\
\hline
\end{tabular}




\begin{tabular}{llllcccccc}
75 & maiale & pig & noun & 15 & 13 & 6 & 3 & 2.5 & 6.0 \\
76 & manette & handcuffs & noun & 0 & 0 & 7 & 3 & 5.1 & 5.8 \\
77 & pappagallo & parrot & noun & 2 & 2 & 10 & 4 & 3.5 & 5.8 \\
78 & pavone & peacock & noun & 1 & 1 & 6 & 3 & 4.5 & 5.3 \\
79 & pinguino & penguin & noun & 1 & 1 & 8 & 3 & 3.3 & 5.7 \\
80 & pipa & pipe & noun & 1 & 1 & 4 & 2 & 3.6 & 5.9 \\
81 & piramide & pyramid & noun & 4 & 3 & 8 & 4 & 4.7 & 6.1 \\
82 & rinoceronte & rhinoceros & noun & 0 & 0 & 11 & 5 & 4.6 & 5.6 \\
83 & scarpa & shoe & noun & 17 & 4 & 6 & 2 & 2.1 & 6.2 \\
84 & scoiattolo & squirrel & noun & 0 & 0 & 10 & 4 & 2.9 & 5.7 \\
85 & stivale & boot & noun & 3 & 0 & 7 & 3 & 3.5 & 5.8 \\
86 & tamburo & drum & noun & 0 & 0 & 7 & 3 & 3.3 & 6.2 \\
87 & tavolo & table & noun & 59 & 34 & 6 & 3 & 2.1 & 6.4 \\
88 & topo & mouse & noun & 3 & 2 & 4 & 2 & 2.6 & 5.8 \\
89 & zebra & zebra & noun & 0 & 0 & 5 & 2 & 3.6 & 5.8 \\
90 & zucca & pumpkin & noun & 5 & 2 & 5 & 2 & 4.8 & 5.5 \\
\hline
\end{tabular}




\section{CAPTIONS FOR FIGURES}

Figure 1. Brain areas found to be related to either verbs or nouns in the past literature. Different symbols represent different baseline and experimental tasks; activation for verbs is drawn in orange, that for nouns in blue.

Figure 2. Stimulus examples for the experimental and baseline conditions.

Figure 3. Brain areas associated with nouns or verbs in the PNT and in the GCST. (A) nounsminus-baseline (blue), verbs-minus-baseline (orange) in the PNT; (B) nouns-minus-verbs (blue), verbs-minus-nouns (orange) in the PNT; (C) nouns-minus-baseline (blue), verbsminus-baseline (orange) in the GCST; (D) nouns-minus-verbs (blue), verbs-minus-nouns (orange) in the GCST.

Figure 4. Conjunction analyses results: the brain regions consistently associated with verbs in both the PNT and the GCST are reported. The plot indicates the mean BOLD signal at the stereotactic coordinates $\mathrm{x}=6, \mathrm{y}=-40, \mathrm{z}=60$ (right precuneus).

Figure 5. Grammatical-class-by-task interaction effect: the brain areas associated with verbs in the PNT and with nouns in the GCST are reported. The plot indicates the mean BOLD signal at the stereotactic coordinates $x=-52, y=32, z=14$ (left inferior frontal gyrus). 


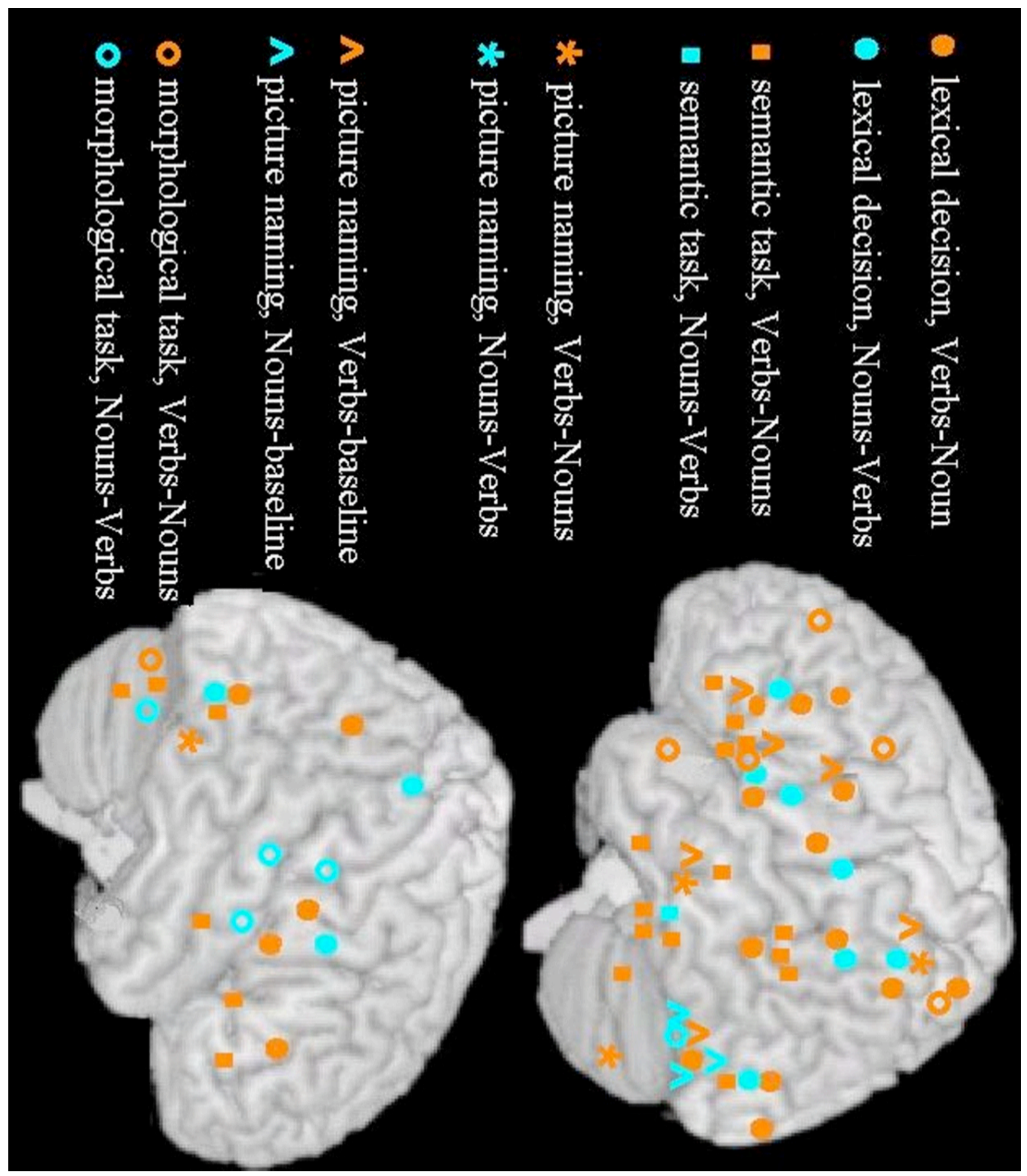




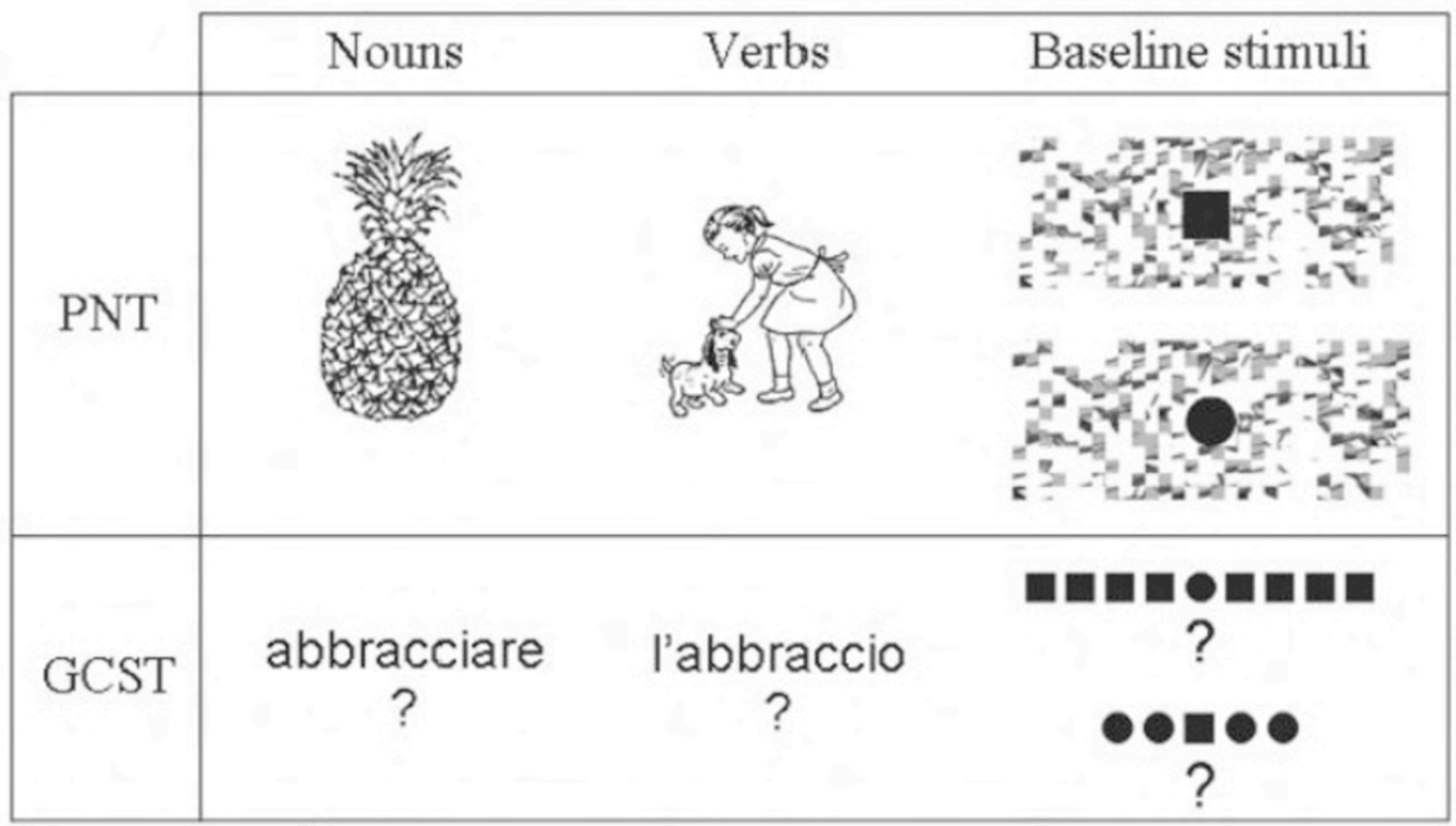




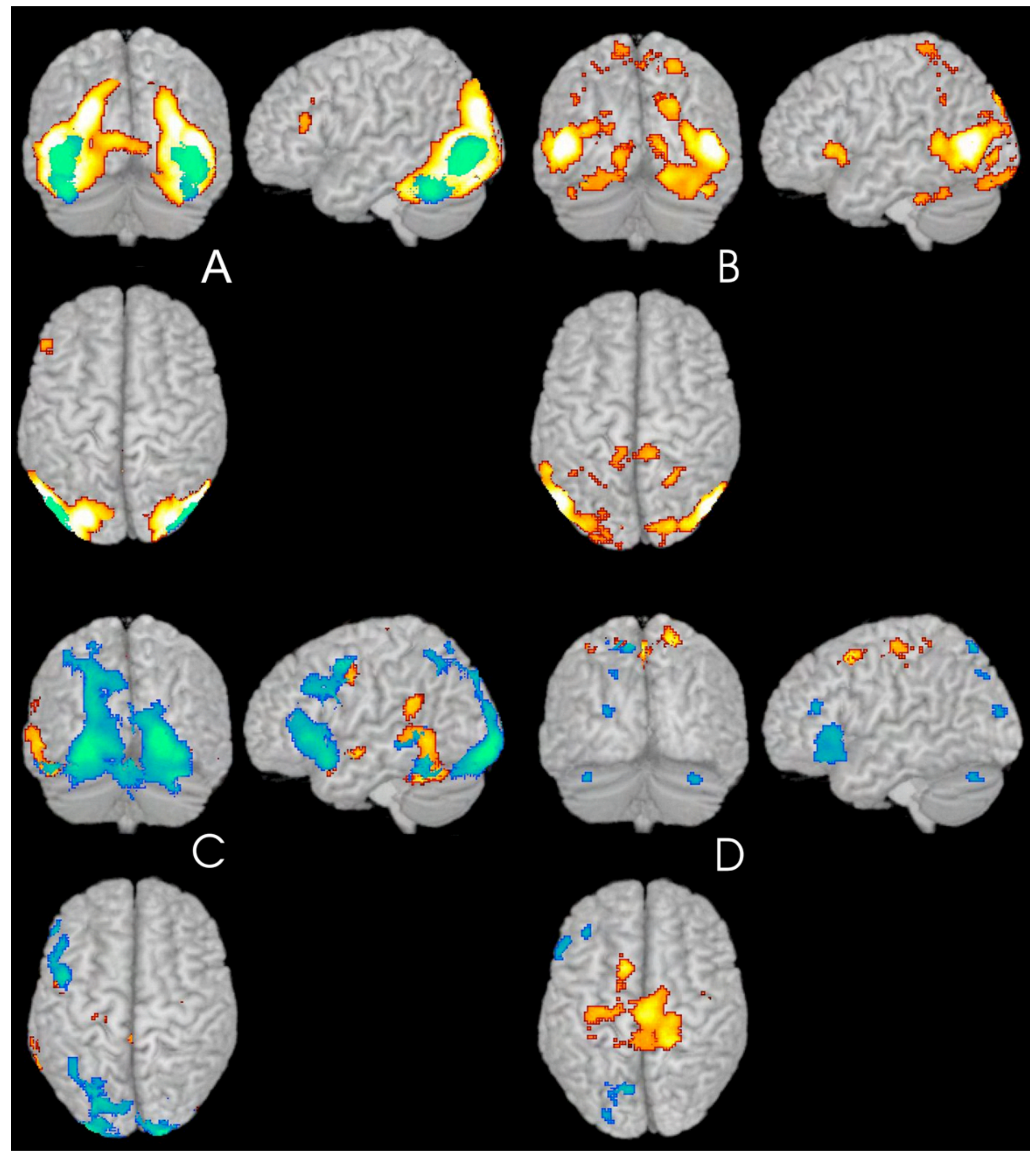




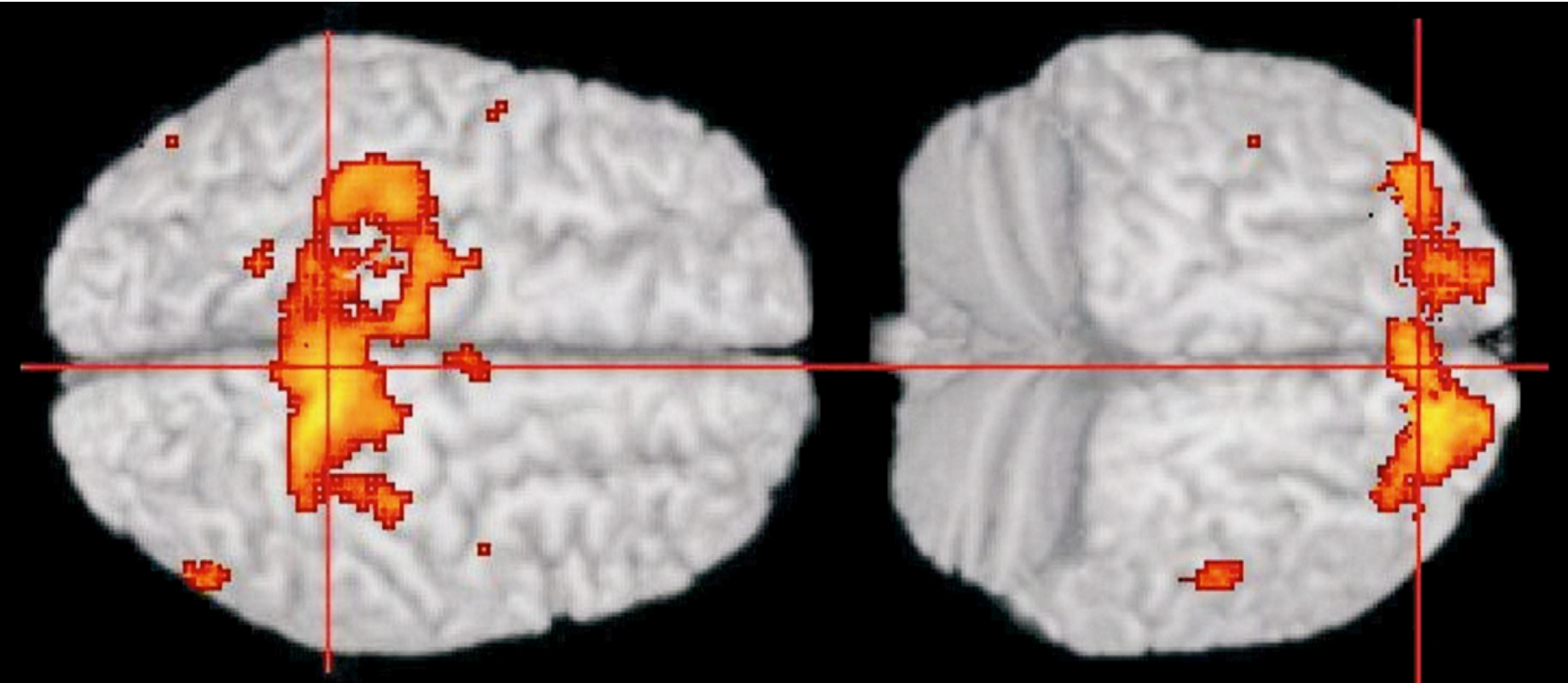

contrast estimate at $6,-40,60$
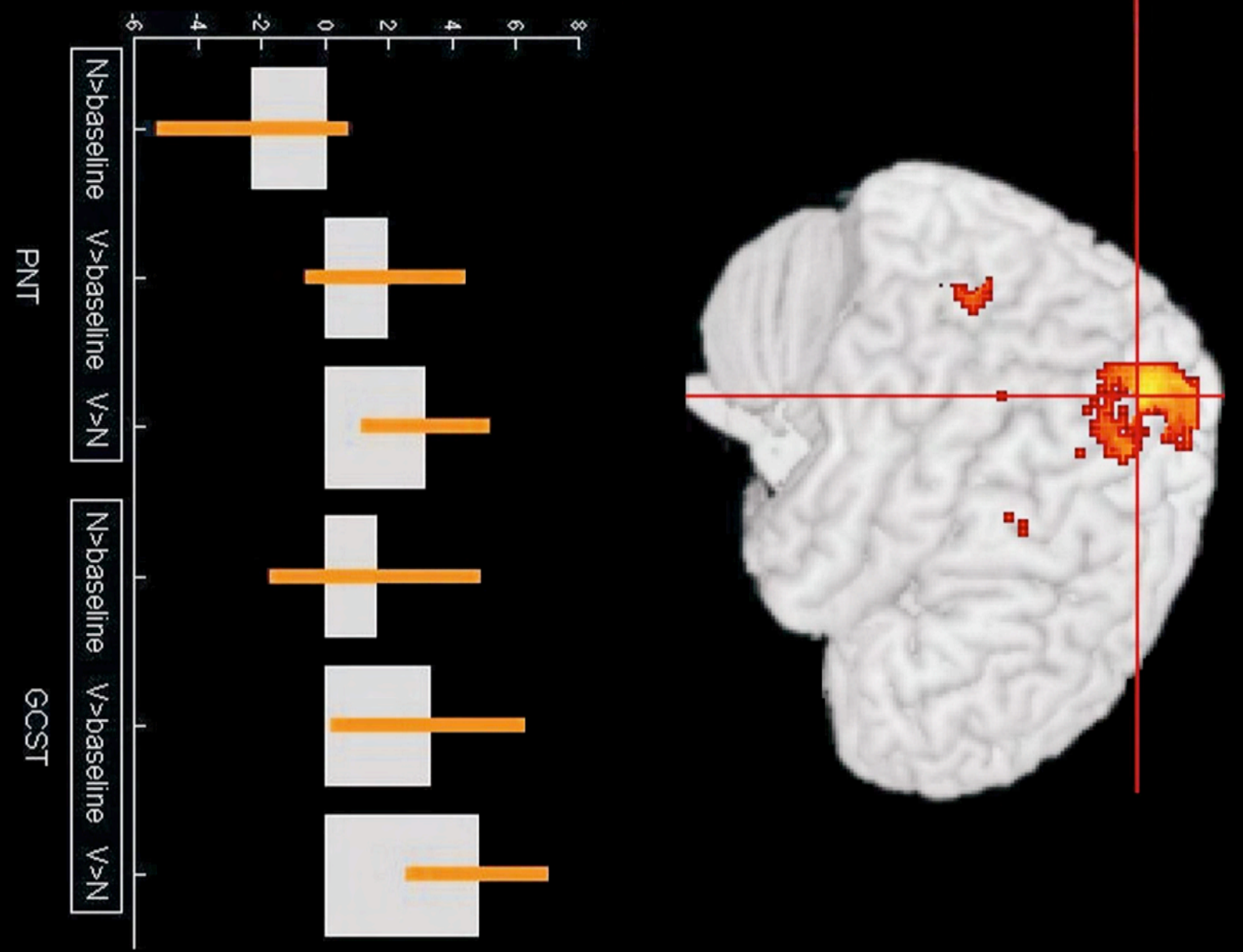


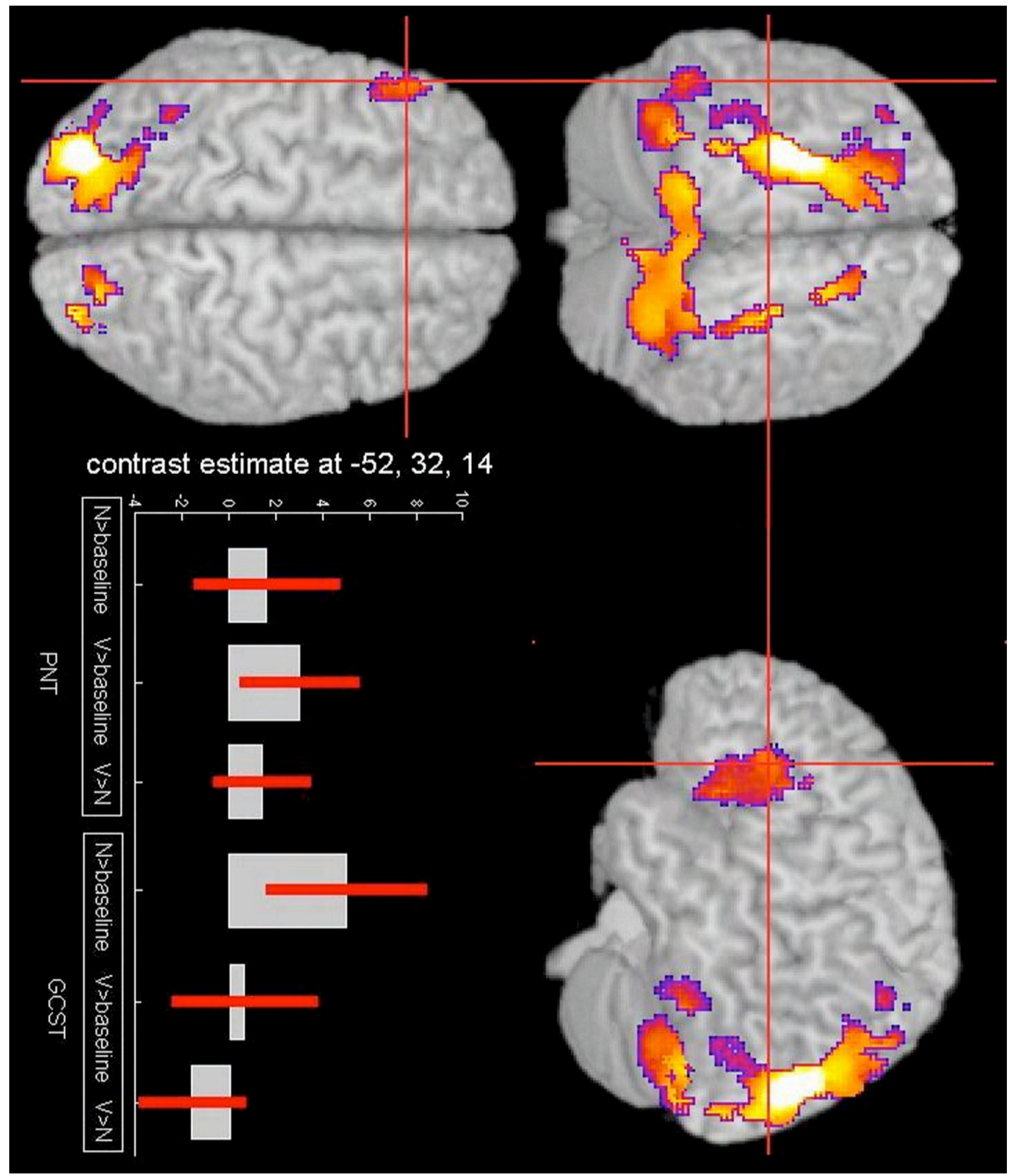

